Research Paper

\title{
Transgenic human embryonic stem cells overexpressing FGF2 stimulate neuroprotection following spinal cord ventral root avulsion
}

\author{
Marta Rocha Araújo a , Sergiy Kyrylenko a,b, Aline Barroso Spejo ${ }^{a}$, Mateus Vidigal Castro a , \\ Rui Seabra Ferreira Junior ${ }^{\mathrm{c}, \mathrm{d}}$, Benedito Barraviera ${ }^{\mathrm{c}, \mathrm{d}}$, Alexandre Leite Rodrigues Oliveira ${ }^{\mathrm{a}, *}$ \\ a Department of Structural and Functional Biology, Institute of Biology, University of Campinas, Campinas, Sao Paulo, Brazil \\ b Department of Biology, Faculty of Medicine, Masaryk University, Brno, Czech Republic \\ c Department of Tropical Diseases, Botucatu Medical School, São Paulo State University (UNESP-Univ. Estadual Paulista), São Paulo State, Brazil \\ ${ }^{d}$ Center for the Study of Venoms and Venomous Animals (CEVAP), São Paulo State University (UNESP-Univ. Estadual Paulista), São Paulo State, Brazil
}

\section{A R T I C L E I N F O}

\section{Article history:}

Received 28 December 2016

Received in revised form 19 April 2017

Accepted 22 April 2017

Available online 24 April 2017

\section{Keywords:}

Ventral root avulsion

Neurotrophic factors

Fibroblast growth factor 2

Embryonic stem cells

Neuroprotection

Motoneurons

\begin{abstract}
A B S T R A C T
Ventral root avulsion (VRA) triggers a strong glial reaction which contributes to neuronal loss, as well as to synaptic detachment. To overcome the degenerative effects of VRA, treatments with neurotrophic factors and stem cells have been proposed. Thus, we investigated neuroprotection elicited by human embryonic stem cells (hESC), modified to overexpress a human fibroblast growth factor 2 (FGF-2), on motoneurons subjected to VRA. Lewis rats were submitted to VRA (L4-L6) and hESC/FGF-2 were applied to the injury site using a fibrin scaffold. The spinal cords were processed to evaluate neuronal survival, synaptic stability, and glial reactivity two weeks post lesion. Then, qRT-PCR was used to assess gene expression of $\beta 2$-microglobulin ( $\beta 2 \mathrm{~m})$, TNF $\alpha$, IL1 $\beta$, IL6 and IL10 in the spinal cord in vivo and FGF2 mRNA levels in hESC in vitro. The results indicate that hESC overexpressing FGF2 significantly rescued avulsed motoneurons, preserving synaptic covering and reducing astroglial reactivity. The cells were also shown to express BDNF and GDNF at the site of injury. Additionally, engraftment of hESC led to a significant reduction in mRNA levels of TNF $\alpha$ at the spinal cord ventral horn, indicating their immunomodulatory properties. Overall, the present data suggest that hESC overexpressing FGF2 are neuroprotective and can shift gene expression towards an anti-inflammatory environment.
\end{abstract}

(C) 2017 Elsevier Inc. All rights reserved.

\section{Introduction}

Lesions to the interface between the central and peripheral nervous systems cause extensive degeneration of spinal motoneurons (Kishino et al., 1997; Oliveira and Langone, 2000), resulting in permanent paralysis. Such injuries show substantial wasting traits and still lack effective treatments. Therefore, development of therapies, which limit the damage to the central nervous system (CNS) and increase the regenerative potential of injured neurons, is in the focus of global research.

Spinal root avulsion occurs as a result of traction forces that act on the region between the spinal cord and the rootlets. This results in denervation and interruption of retrograde flow of the neurotrophic factors produced by the target organ (Livesey and Fraher, 1992). Root avulsion in adults often follows high-energy traumas, as seen in motorcycle accidents, although it may also happen e.g. during complicated

\footnotetext{
* Corresponding author at: Departamento de Biologia Estrutural e Funcional, Instituto de Biologia - Unicamp, Rua Monteiro Lobato, 255, Cp6109, 13083-970, Distrito de Barão Geraldo, Campinas, Brazil.

E-mail address: alroliv@unicamp.br (A.L.R. Oliveira).
}

child delivery (Carlstedt, 2008; Malessy et al., 2009). Ventral root avulsion exclusively affects motor fibers leading to the retrograde degeneration of axotomized spinal motoneurons. Experimental VRA is an efficient model for studying degenerative changes of motoneurons and their underlying mechanisms (He et al., 2000; Koliatsos et al., 1994); as well as a reliable model for testing various therapeutic agents, including trophic factors (Koliatsos et al., 1994; Watabe et al., 2005).

In addition to the general loss of cells, any surviving motoneurons suffer a substantial decrease of presynaptic terminals, which further reduces or even abolishes synaptic transmission (Carlstedt, 2009). In this scenario, the microglial cells and astrocytes become reactive, increasing the degree of synapse elimination (Novikov et al., 2000; Ohlsson and Havton, 2006).

It has become clear that multifaceted strategies are necessary to successfully recover appropriate motor functions following VRA. In this regard, the priority post lesion is to preserve as many axotomized motoneurons as possible. Thus, recent studies have proposed different approaches, including cell therapy (Rodrigues Hell et al., 2009; Spejo et al., 2013) and therapy with neurotrophic factors (Liu et al., 2011; Romero et al., 2001). However, the use of embryonic stem cells has not yet been tested. 
Embryonic stem cells (ESC) are pluripotent cells isolated from inner cell mass of blastocysts (Evans and Kaufman, 1981; Thomson et al., 1998). Because of their pluripotency and ability for self-renewal, these cells were considered as an ideal source for cell replacement therapies (Ovchinnikov et al., 2012; Weissman, 2000). The ESCs, under appropriate culture protocols, maintain a regular karyotype and appear not to be susceptible to mitochondrial or epigenetic changes (Zeng and Rao, 2007). Importantly, the cell lines of hESC can be genetically manipulated (Robertson, 1987). Thus, several technologies have been developed to generate stably transfected hESC clones (Moore et al., 2010).

Among the variety of trophic factors, FGF2 is particularly conspicuous. Its receptors (FGFRs) are expressed in various cell types, including neurons (Eckenstein, 1994; Gómez-Pinilla et al., 1992), normal and reactive astrocytes (Follesa et al., 1994; Leme and Chadi, 2001; Liesi and Kauppila, 2002; Reilly et al., 1998) and microglia (Liu et al., 1998). FGF2 promotes proliferation of multipotent neural stem cells (Shihabuddin et al., 1997) and neural progenitors (Martens et al., 2002) in the spinal cord of the adults following lesions to the nervous system (Dono, 2003; Zai et al., 2005). In vitro, FGF2 increases neuronal survival, protects neurons against excitotoxicity, decreases apoptotic cell death and promotes myelination (Mattson and Scheff, 1994; Walicke, 1988). Moreover, FGF2 is also capable of stimulating synaptic plasticity (Ishiyama et al., 1991; Terlau and Seifert, 1990) and plays a major role in acute axonal regeneration after spinal cord injury (Zai et al., 2005).

Based on its robust neuroprotective properties, the FGF2 has been attempted as a therapeutic agent and showed mostly positive results (Fawcett and Asher, 1999; Rabchevsky et al., 2000; Tsai et al., 2008). In this sense, the present work aimed at improving motoneuron survival after VRA via application of transgenic hESCs that overexpress FGF2 in an inducible mode. hESCs were introduced to the lesion site by using a fibrin sealant scaffold. The results obtained can shed light on mechanisms of neuroprotection and can contribute to development of therapeutic strategies after VRA.

\section{Material and methods}

\subsection{Experimental animals}

Adult female Lewis rats 9-12 weeks old with body weight about $200 \mathrm{~g}$ were used for this study. All procedures were done in accordance with the ethical principles regulated by the National Council of Animal Experimentation (CONCEA) and with the approval of the Ethics Committee on Animal Experimentation of University of Campinas (CEUA/ UNICAMP, protocol no 3373-1). Doxycycline (DOX) was used as an inducer of expression of FGF2 in the transgenic hESC. To induce overexpression of FGF2 in the hESCs in vivo, the inducer was combined with the pelleted food and given to animals ad libitum, for the whole duration of the experiment ( 2 weeks), at a concentration of $625 \mathrm{mg}$ of DOX per $\mathrm{kg}$ of pelleted food, as described (Cawthorne et al., 2007). Recombinant FGF2 (rFGF2) was applied directly to the site of injury in a select control group. The following experimental groups ( $\mathrm{n}=10$ in each group) were established: I, Avulsion with fibrin sealant (AV + FS); II, AV + FS + hESC + DOX (cells on); III, AV + FS + DOX; IV, AV + FS + hESC (cells off); V, $\mathrm{AV}+\mathrm{FS}+\mathrm{rFGF2}$. The tissue samples from the contralateral side of the spinal cord, relative to the lesion side, were used as controls. For RTqPCR experiments, samples from animals without injury $(n=5)$ were used as controls.

\subsection{Ventral root avulsion}

The animals were anesthetized with a combination of xylazine (Anasedan®, $10 \mathrm{mg} / \mathrm{kg}$, Sespo Indústria e Comércio Ltda, Paulinia, SP, Brazil) and ketamine (Dopalen ${ }^{\circledR}, 90 \mathrm{mg} / \mathrm{kg}$, Sespo Indústria e Comércio Ltda, Paulinia, SP, Brazil). A dorsal incision, parallel to the spine, was performed in the upper lumbar/thoracic region. The paravertebral musculature of the spine was removed to expose the lower thoracic and upper lumbar vertebrae. Laminectomy of approximately three vertebrae was performed to expose the lumbar intumescence. The dural sac was opened through a longitudinal incision and, after dissection of the denticulate ligament, the ventral roots were moved and followed carefully until the respective rootlets could be detected and avulsed. The unilateral avulsion was performed by pulling out the rootlets at the L4, L5 and L6 spinal segments, with a fine forceps (No.4). After the surgical procedures, the moved roots were replaced in their original position, after which the musculature, fascia and skin were sutured in layers, and the animals were kept in the Laboratory of Nerve Regeneration animal house for two weeks.

\subsection{Vector construction}

The Phusion High Fidelity DNA Polymerase (Finnzymes/Thermo Fisher Scientific, Vantaa, Finland) was used to amplify DNA fragments intended for cloning and/or transfections. For constructing the hFGF2 bacterial overexpressing vector, a PCR fragment $475 \mathrm{bp}$ in length was obtained using primers FGF2-cds-2C, 5'-gaacatatggc agccgggagcatcac-3' (with Ndel recognition site, underlined), and FGF2cds-2D, 5'-atccctcgagctagctcttagcagacattgg-3' (with Xhol recognition site, underlined); and a template DNA from the ORFeome clone OCABo5050E0522D obtained from Source BioScience (Nottingham, United Kingdom). Its NdeI-Xhol subfragment 470 bp in length was then cloned into pET28b (Novagen/Merck Millipore, Darmstadt, Germany) using appropriate restriction endonucleases. The resulting vector pTe133 (GenBank accession number KX834270) was induced with IPTG in E. coli BL21(DE3) using EnPresso growth system from BioSilta Oy (Oulu, Finland) based on enzyme-controlled glucose autodelivery. The soluble recombinant protein was purified using Ni affinity column. The (His)x6 tag was cleaved off by thrombin, and the resulting rFGF2 was further purified using heparin affinity column. The biological activity of the purified rFGF2 was verified using 2 methods: via cell proliferation assay in hESC; and then via the Erk phosphorylation assay in hESC.

To obtain a stable hES cell line overexpressing FGF2-GFP fusion in an inducible mode, a Tet-On system (Clontech/Takara Bio, Mountain View, CA, USA) was used. For constructing a vector for inducible overexpression of hFGF2, a PCR fragments obtained with primers FGF2-cds-G, 5'cagaattcatggcagccgggagcatc-3' (with EcoRI recognition site, underlined) and FGF2-cds-H, 5'-tgggtaccaagctctta gcagacattgg-3 (with KpnI recognition site, underlined), containing ORF of hFGF2, was cloned (477 kb) into respective sites of pEGFP-N1 (Clontech), giving rise to an intermediate vector pTe104, overexpressing hFGF2-GFP fusion in a constitutive (non-inducible) mode. Then, the pTe104 was used as a template to amplify the fragment containing hFGF2-GFP fusion ORF with the primer FGF2-cds-G and a primer cdsGFP-B, 5'-cgtctagattacttgtacagctcgtccatg- ${ }^{\prime}$ (with Xbal recognition site, underlined). This fragment after digestion (1227 bp in length) was cloned into respective sites of pTRE-Tight (Clontech), giving rise to a vector pTe106 (GenBank accession number KX844812). For stable cell transfections, the DNA of the pTe106 vector was used as a template for amplifying a linear transfection fragment 2275 bp in length containing essential parts of the vector and omitting the unnecessary bacterial sequences, with primers TRE-Lin-FWD, 5'gaagcatttatcagggttattgtctc- $3^{\prime}$ and TRE-Lin-REV, 5'-agggagaaaggcgga caggtatc- $3^{\prime}$.

\subsection{Preparation and administration of the fibrin sealant}

The fibrin sealant was manufactured using snake venom from rattlesnake Crotalus durissus terrificus and was kindly provided by the Center for Study of Venoms and Venomous Animals (CEVAP - Unesp, Brazil); its components and application formula are stated in the respective patents (record numbers BR1020140114327 and BR1020140114360). At the moment of application, immediately after the avulsion, the fibrin sealant was prepared by mixing its three components at the ventral surface of the lumbar intumescence: fibrinogen derived from buffalo blood 
( $3 \mu \mathrm{l}), 25 \mathrm{mM}$ calcium chloride $(2 \mu \mathrm{l})$ and a thrombin-like protein from rattlesnake venom $(1 \mu \mathrm{l})$. The sealant polymerizes within a few seconds after application (Barros et al., 2009, 2011; Biscola et al., 2017; Ferreira et al., 2017; Seabra Ferreira, 2014).

\subsection{Manipulations with stem cells}

The hES cell line CCTL12 was cultured in monolayers on Matrigel as described (Kunova et al., 2013). The karyotype of the cells was analyzed at Institut für Humangenetik und Anthropologie, Jena, Germany. For transfection of the stem cells, we initially employed the nucleofection (Lonza, Basel, Switzerland) and compared it to chemical transfection methods with FuGene 6, FuGene HD (Roche, Basel, Switzerland), Lipofectamine 2000 (Thermo Fisher Scientific, Waltham, MA USA) and NanoJuice (Novagen/Merck Millipore, Darmstadt, Germany) reagents according to manufacturer protocols. For the pilot experiments, cells were transfected with pEGFP-N1 vector, and quantification of efficiency of transfection was done by flow cytometry with Cytomics FC500 Flow Cytometry Analyzer (Beckman Coulter, Brea, CA, USA) 48 h post transfection by monitoring percentage of GFP positive cells. For this, cells were collected by TrypLE (Invitrogen/Thermo Fisher Scientific) and resuspended in conditioned HES medium (Kunova et al., 2013) supplied with $10 \mu \mathrm{g} / \mathrm{ml}$ propidium iodide.

For stable selection, a concentration of G-418 and Blasticidin selection agents were pre-determined with killing curves, such that the sensitive (wild type) cells were slowly cleared away during 2 weeks. The killing curves were determined first in wide ranges and then in narrow ranges of concentrations. The G-418 was used at $140 \mu \mathrm{g} / \mathrm{ml}$ and Blasticidin at $1.2 \mu \mathrm{g} / \mathrm{ml}$. The cells were plated at 20,000 cells $/ \mathrm{cm} 2$ on Matrigel covered plates, and the selection agents were added $24 \mathrm{~h}$ post plating.

The inducible overexpression in Tet-On system is regulated by rtTA transactivator, therefore in the first round of stable selection the cells were transfected with the HindIII linearized regulatory vector pEF1aTet3G (Clontech) and selected against G-418. For this, the cells were plated at 20,000 cells $/ \mathrm{cm}^{2}$ into $24 \times$ plate. $24 \mathrm{~h}$ post plating the cells were transfected with FuGene HD reagent. After additional $24 \mathrm{~h}$, the transfected cells were collected with TrypLE and plated into $6 \times$ plate with 2-fold serial dilutions; and the selection agent was added $24 \mathrm{~h}$ post plating. The medium was changed 2 times per week. Two weeks after, the individual colonies were collected and the dissociated cells were transferred to $96 \times$ well plates.

The growing colonies were divided into 3 parallel $96 \times$ plates, and the individual clones were screened for the efficiency of induction by transient transfection with pTRE-Luc vector (Clontech) followed by induction with DOX at $1 \mu \mathrm{g} / \mathrm{ml}$ and determination of luciferase signal using Bright-Glo Luciferase Assay System (Promega, Fitchburg, Wisconsin, United States). The luciferase signal was normalized to metabolic activity of the cells in the same well determined by a resazurin assay. For this, the resazurin was added to each well at $5 \mu \mathrm{g} / \mathrm{ml}$, and the fluorescence was determined with 595/535 nm excitation/emission wavelength, respectively after $4 \mathrm{~h}$ incubation in $\mathrm{CO}_{2}$ incubator at $37^{\circ} \mathrm{C}$. The clones were screened for the lowest basal expression and the highest induction rate, as well as for their ability to retain their properties after cycles of cryopreservation.

The cells of the selected stable clone E12-1 (positive for the rtTA transactivator) was further stably transfected with the pTe106 target vector. The transfection-selection procedure was done similarly as described above. As the pTe106 (a derivative of pTRE-Tight) vector does not possess any selection marker, its linear fragment (see above) was co-transfected with a Blasticidin linear selection marker. The linear selection marker for Blasticidin was obtained as a PCR fragment $1309 \mathrm{bp}$ long with primers BlastLin-A, 5'-tataagggattttgccgatttcgg- $3^{\prime}$ and BlastLin-B, 5'-gtatgttgtgtggaattgtgagc- $3^{\prime}$ and DNA of vector pcDNA6/ TR (Invitrogen) as a template. The resulting double-stable clone E12-
1-1 (overexpressing human FGF2 in an inducible mode) was used in further experiments to support neuronal survival and regeneration.

\subsection{Human embryonic stem cell transplantation and FGF2}

Immediately following VRA, $3 \times 10^{5}$ hES cells resuspended in 3-5 $\mu \mathrm{l}$ of DMEM were engrafted directly at the lesion site together with the fibrin sealant matrix/scaffold. To induce overexpression of FGF2 in the hESCs in vitro, the inducer doxycycline was added to the growth medium at $1 \mu \mathrm{g} / \mathrm{ml}$ for $24-48 \mathrm{~h}$. For experiments in vivo, DOX was given to animals combined with the pelleted food (see details above). Induction was confirmed by GFP expression in the hESC. In animals of group V, human recombinant FGF2 was applied directly, mixed together with the fibrin sealant matrix before its polymerization, similarly to the hESC cases. For this, $3 \mu \mathrm{l}$ of rFGF2 at $10 \mu \mathrm{g} / \mu \mathrm{l}$ (Goldshmit et al., 2014) in PBS was used immediately following injury.

\subsection{Specimen preparation}

Two weeks after VRA, the animals were euthanized. For this, they were anesthetized with a combination of xylazine (Anasedan ${ }^{\circledR}$, $10 \mathrm{mg} / \mathrm{kg}$ ) and ketamine (Dopalen ${ }^{\circledR}, 90 \mathrm{mg} / \mathrm{kg}$ ). The vascular system was subjected to transcardial perfusion with Phosphate Buffered Saline (PBS) ( $\mathrm{pH}$ 7.4). In order to evaluate neuronal survival and immunohistochemistry ( $n=5$ per group) the rats were perfused with $4 \%$ formaldehyde in $0.1 \mathrm{M}$ sodium phosphate buffer $(\mathrm{PB}) \mathrm{pH}$ 7.4. The lumbar intumescence was dissected out and post fixed in the same fixative for $12 \mathrm{~h}$ at $4{ }^{\circ} \mathrm{C}$. The specimens were then washed in PBS and subjected to gradually increased concentrations of sucrose (10,20 and 30\% for $24 \mathrm{~h}$ each) in $0.1 \mathrm{M}$ PB for cryoprotection.

The samples were then embedded into Tissue-Tek ${ }^{\circledR}$ O.C.T. (Sakura Finetek USA, Inc., Torrance, CA USA) and frozen at $-35 / 40{ }^{\circ} \mathrm{C}$. Transverse sections, $12 \mu \mathrm{m}$ thick, of the spinal cord (lumbar intumescence) were done in cryostate and subsequently stored at $-20{ }^{\circ} \mathrm{C}$ until use. For RT-qPCR analysis, the lumbar intumescence was rapidly dissected out following perfusion with cold PBS. Both left and right spinal cord sides were separated, as well as the areas of ventral and dorsal horns. The ipsilateral and contralateral ventral segments were placed in separate microtubes, snap-frozen in liquid nitrogen, and stored at $-80{ }^{\circ} \mathrm{C}$ until use. The same spinal cord regions of uninjured animals were used as a control group $(n=5)$.

\subsection{Motoneuron survival}

Spinal cord transverse sections were stained in cresyl violed - Nissl staining for $3 \mathrm{~min}$ at room temperature. The motoneurons in the lateral motor nucleus of the ventral horn in the ipsilateral (injured) and contralateral (uninjured) sides were counted in alternate sections from each specimen. 12 sections with an $180 \mu \mathrm{m}$ spacing between them were used for counting in each specimen. Only those motoneurons which had visible nucleus and nucleolus were counted. For correction of possible duplicate counting of neurons since the same cell may be present in two sections, the Abercrombie and Johnson's formula was used: $\mathrm{N}=\mathrm{nt}$ $/(t+d)$, where $N$ is a precise number of counted neurons, $n$ is the number of counted cells, $t$ is the thickness of the sections, and $d$ is the average diameter of the neuron. Since the size difference significantly impacts on the number of cells, d was specifically calculated for each experimental group (separately for ipsilateral and contralateral sides). For this, the diameter of fifteen randomly chosen motoneurons from each group was measured (Image Tool software, version 3.00, The University of Texas Health Science Center, TX) and the mean was calculated. The percentage of surviving cells was analyzed as a ratio of absolute numbers of motoneurons, counted per section, on the lesioned versus the non-lesioned sides, respectively, and multiplying the obtained number by 100 . The data are presented as a mean \pm standard error (SE) for each group. 


\subsection{Immunohistochemistry}

The slides with the transverse sections of spinal cord were acclimatized, washed with $0.1 \mathrm{M} \mathrm{PB}$ ( 3 times for 5 min each) and incubated with $3 \%$ bovine serum albumin (BSA) in the same buffer for $1 \mathrm{~h}$. Then, the slides were incubated for $3 \mathrm{~h}$ with the primary antibodies: mouse anti-synaptophysin; rabbit anti-GFAP (glial fibrillary acidic protein); rabbit anti-Iba1 (ionized calcium-binding adapter molecule 1); sheep anti-GDNF (glial-derived neurotrophic factor) and rabbit anti-BDNF (brain-derived neurotrophic factor) (Supplementary Table St3). The primary antibodies were diluted in a solution containing $1 \%$ BSA and $0.2 \%$ Triton $\mathrm{X}-100$ in $0.1 \mathrm{M}$ PB. Immunostaining was done in a moist chamber at room temperature. After washing with $0.1 \mathrm{M} \mathrm{PB}$ (3 times for 5 min each), the sections were incubated with $\mathrm{Cy} 3$-conjugated secondary antiserum (1:250, Jackson Immunoresearch, West Grove, PA, USA), according to the origin of the primary antibody, diluted in $1 \%$ BSA and $0.2 \%$ Triton X-100 in $0.1 \mathrm{M}$ PB for 45 min. The slides were washed again in $0.1 \mathrm{M} \mathrm{PB}$, mounted in $0.1 \mathrm{M}$ PB with glycerol (3:1) and subsequently analyzed with a fluorescence microscope (Leica DM5500B) coupled with a Leica DFC345FX (Leica Microsystems CMS $\mathrm{GmbH}$ ) camera. Rhodamine filter (CY3) was used to analyze labeling of BDNF, GDNF, reactive astrogliosis (GFAP), microglial reaction (IBA1) and synaptic covering of motoneurons (synaptophysin), while fluorescein filter was used for visualizing hESC for their GFP fluorescence. Representative images were captured from the sections from each side (both injured and non-injured), 3 sections of the spinal cord ventral column at lamina IX were used per each experimental animal.

For quantification of synaptophysin, integrated pixel density was measured at eight equidistant areas around the positive neurons in the anterior horn of the spinal cord, according to report of Oliveira et al. (2004). For quantification of GFAP and IBA-1, the integrated pixel density was measured in the entire picture at lamina IX region, as described (Oliveira et al., 2004 Freria et al., 2010). The ratio of the integrated pixel density between the ipsilateral versus the contralateral sides was calculated for each animal. The data are represented as the mean \pm standard error (SE) for each group.

\subsection{Real time $P C R$}

We evaluated relative levels of mRNA of the TNF $\alpha$, IL1 $\beta$, IL6, IL10, $\beta 2 \mathrm{~m}, \mathrm{BDNF}$ and GDNF genes (Supplementary Table St4) in vivo in the lumbar spinal cord of the Lewis rats two weeks after the avulsion; while mRNA levels of FGF2 were measured in cell culture in vitro. The samples were mechanically homogenized/dissolved with a $200 \mu \mathrm{l} \mathrm{pi-}$ pette tip in Tryzol (QIAzol Lysis Reagent, Qiagen, Hilden, Germany) and the total RNA was extracted using Tryzol protocol and RNeasy Lipid Tissue Mini Kit (Qiagen) according to the manufacturer's instructions. Quantification of the RNA was performed using a nanophotometer; and assessment of the RNA integrity was conducted by $1 \%$ agarose gel electrophoresis. For this, the RNA samples were denatured in $50 \%$ formamide, $1 \times$ TBE, loading dye and ethidium bromide, heated at $62{ }^{\circ} \mathrm{C}$ for $5 \mathrm{~min}$ and kept on ice for an additional $5 \mathrm{~min}$. The RNA was then resolved in $1 \%$ agarose gel in $0.5 \times$ TBE buffer for $55 \mathrm{~min}$ at $5 \mathrm{~V} / \mathrm{cm}$. The gel was observed on an UV transilluminator, and integrity of the RNA samples was accessed as a ratio of intensities of $28 \mathrm{~S}$ and $18 \mathrm{~S}$ rRNA bands.

Complementary DNA (cDNA) synthesis was performed using the RevertAid H Minus First Strand cDNA Synthesis Kit (Fermentas/Thermo Fisher Scientific, Vilnius, Lithuania) following the manufacturer's instructions. The cDNA was synthesized with $2.0 \mu \mathrm{g}$ of total RNA using oligo (dT) $)_{18}$ as a primer. The cDNA was used as a template for the PCR reactions in real time with TaqMan ${ }^{\circledR}$ Gene Expression Master Mix (2X) (Life Technologies/Thermo Fisher Scientific, Carlsbad, CA, USA) and TaqMan assays (primers + hydrolysis probes) for the genes listed in Supplementary Table St4, in the volume of $20 \mu$ l. Forty-five cycles of amplification were carried out $\left(95^{\circ} \mathrm{C}\right.$ for $10 \mathrm{~min}$, followed by $95^{\circ} \mathrm{C}$ for $15 \mathrm{~s}$ and $60^{\circ} \mathrm{C}$ for $1 \mathrm{~min}$ ). The choice of the reference genes was carefully elaborated for the unchanged expression under various experimental conditions. The HPRT1 reference genes (for medullary samples) and RICTOR (for cells) were labeled with VIC fluorophore and the target genes with FAM fluorophore. The quantitative PCR was done in the Mx3005P instrument (Agilent, Santa Clara, CA, USA) and the results were calculated with MxPro program (Agilent). Relative quantification of the genes of interest was performed using $2^{-\Delta \Delta \mathrm{Ct}}$ method (Livak and Schmittgen, 2001).

\subsection{Statistical analysis}

Statistical analysis was performed with Graphpad Prism 4.0 software. Neuronal survival and immunohistochemistry data were evaluated using the one-way analysis of variance (one-way ANOVA). To evaluate differences among the groups, we used a Bonferroni post-hoc test. RT-qPCR data were evaluated using the one-way ANOVA, while a Newman-Keuls post-hoc test was used to assess differences among the groups. The significance levels were accepted as follows: ${ }^{*} \mathrm{p}<0.05$; ${ }^{* *} \mathrm{p}$ $<0.01$ and ${ }^{* * *} \mathrm{p}<0.001$.

\section{Results}

\subsection{FGF2 overexpression, grafting and migration of hESCS}

We overexpressed in E. coli and purified human recombinant FGF2. We confirmed that our rFGF2 was biologically active, as it was able to enhance proliferation of human embryonic stem cells (Supplementary Fig. S1). We then showed that it can robustly induce phosphorylation of Erk kinase in hESC. The specific activity of the obtained rhFGF2 was comparable to the commercial preparation of FGF2.

We then constructed an eukaryotic expression vector pTe106 (pTRETight-FGF2-GFP). The obtained vector was confirmed to overexpress FGF2-GFP fusion in an inducible mode after transient transfection into hESC (Supplementary Fig. S2). A double stable clone of hESC was established using regulatory vector pEF1a-Tet3G and the target vector pTe106. For the choice of the transfection method, we initially employed nucleofection (Supplementary Table St1), and compared it with different chemical transfection methods (Supplementary Fig. S4, Supplementary Table St2). As a result, the FuGene HD transfection reagent was chosen for generating double stable clones of hESC. The concentrations of the selecting agents were carefully adjusted via killing curves. Importantly, we found that the dynamics of the killing curve depended largely on the time of the addition of antibiotic after plating. This way we obtained a double stable clone E12-1-1. The karyotype of the hESC was verified (Supplementary Fig. S3). Through in vitro assays, it was demonstrated that the clone E12-1-1 of the stably transfected hESC robustly overexpress FGF2 after induction with doxycycline, detected by the expression of the GFP (Fig. 1A, B). After engraftment of the hESC directly at the site of VRA, two weeks after injury (during which the inducer (DOX) was supplied to animals via pelleted food), it was possible to find a significant number of GFP positive cells at the injury site, as well as in the spinal cord gray matter (Figs. 1C-D and 2A-D). This suggests that the engrafted bioengineered hESC can overexpress neurotrophic growth factors in vivo. It also suggests that hESC can migrate into the spinal cord tissues and remain there for a period of at least 2 weeks.

\subsection{Detection of BDNF and GDNF}

Immunohistochemical analyses were performed in order to study whether the hESCs can contribute to the production of neurotrophic factors other than FGF2, such as BDNF (brain-derived neurotrophic factor) and GDNF (glial-derived neurotrophic factor). For this purpose, immunostaining was performed with relevant antibodies. We observed that a remarkable number of GFP positive hESC were also positive for BDNF and GDNF at the cell application site two weeks after injury (Fig. 

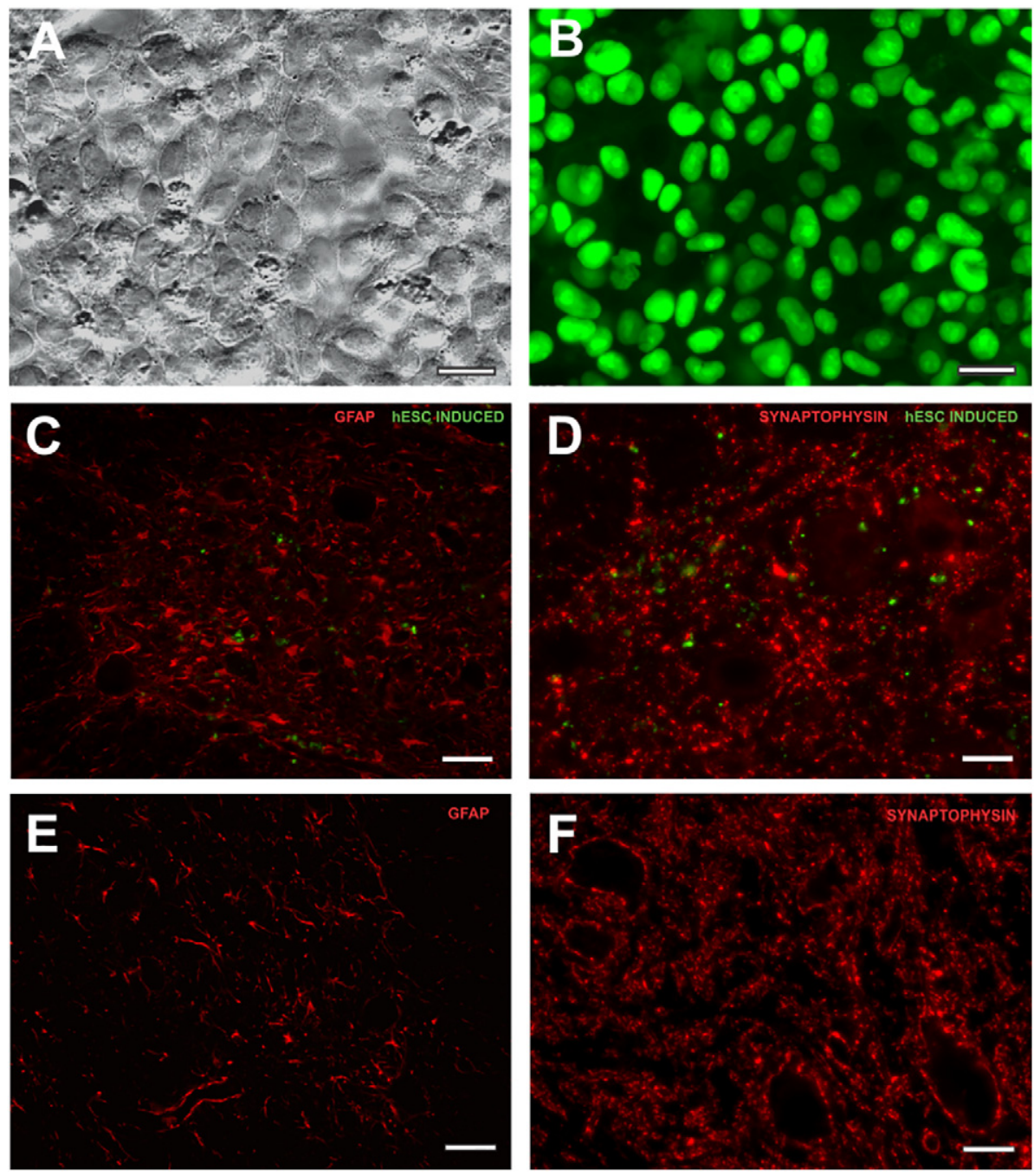

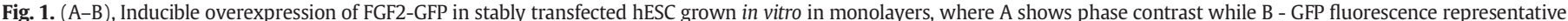

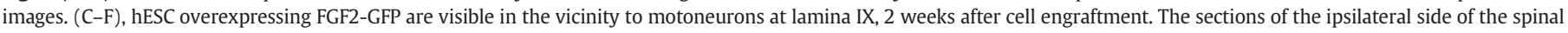
$\operatorname{cord}(\mathrm{C}, \mathrm{D})$ and the contralateral side (E, F) were immunolabeled with anti-GFAP (C, E) and anti-synaptophysin antisera $(\mathrm{D}, \mathrm{F}) . \mathrm{Scale}$ bars: $(\mathrm{A}-\mathrm{B})=20 \mu \mathrm{m}$; $(\mathrm{C}-\mathrm{F})=50 \mu \mathrm{m}$.

2A-F). This might suggest that the stem cells can contribute to neuronal preservation by overexpressing various neurotrophic factors.

\subsection{Neuronal survival}

The effect of hESC treatment was analyzed through the Nissl staining, with which it was possible to determine the percentage of neuronal survival at lamina IX of the ventral horn. The rate of survival was calculated by the percentage ratio between the numbers of motoneurons in the ipsilateral versus the contralateral sides. It is of note, that the contralateral side of all groups showed no statistical differences in the absolute number of the preserved motoneurons. Thus, evaluation of the neuronal survival at the injured side was done using the contralateral side as a reference. As a result, severe degeneration of injured motoneurons was observed in the motor nucleus in all lesioned groups, except in that treated with hESC + DOX (Fig. 3). The percentage ratio between the number of surviving motoneurons in the ipsilateral versus the contralateral sides showed the following survival rates: AV + FS: $42.38 \%$ $\pm 2.26 \%$; AV + FS + hESC + DOX: $63.60 \% \pm 1.71 \%$; AV + FS + DOX: $39.85 \% \pm 4.91 \%$; AV + FS + hESC: $42.39 \% \pm 2.12 \%$; AV + FS + FGF2: $51.59 \% \pm 3.55 \%, \mathrm{n}=5$ per group (Fig. 3 ). Overall, this suggests that treatment with induced bioengineered hESC leads to better survival of motoneurons after neuronal injuries.

\subsection{Synaptic preservation}

To assess changes in number of synapses after VRA and proposed treatments, anti-synaptophysin immunolabeling was evaluated. Immunostaining revealed a higher synaptic density in the contralateral side of avulsed animals, compared to the ipsilateral counterpart. Of note, the staining at the surface of large motoneurons was particularly visible in uninjured cells. In contrast to the contralateral side, the intensity of the synaptophysin expression was reduced on the surface of motoneurons that have undergone avulsion. This indicated a significant decrease of terminals in the avulsed neurons. Importantly we observed preservation of terminals in both groups, treated with doxycycline + hESCs, as well as in groups treated with rFGF2. The percentage ratio between the integrated pixel densities of the synaptophysin immunostaining in the ipsilateral versus the contralateral sides showed the following rates: AV + FS: $42.46 \%$ \pm 3.90\%; AV + FS + hESC + DOX: $75.56 \% \pm 2.34 \%$; AV + FS + DOX: $41.46 \% \pm 2.31 \%$; AV + FS + hESC: $49.24 \% \pm 2.82 \%$; AV + FS + FGF2: $56.55 \% \pm 1.08 \%, \mathrm{n}=5$ per group. Overall, this indicates that FGF2 can contribute to better synaptic preservation after neuronal injuries (Fig. 4).

\subsection{Glial reactivity}

Glial reactivity after VRA was evaluated in the ventral horn of the spinal cord by GFAP immunolabeling. We first confirmed that the 


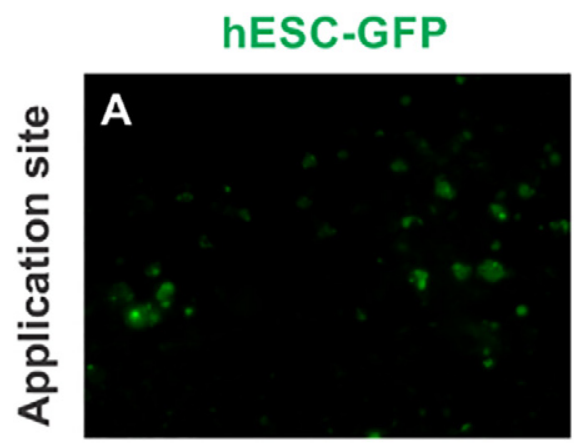

hESC-GFP

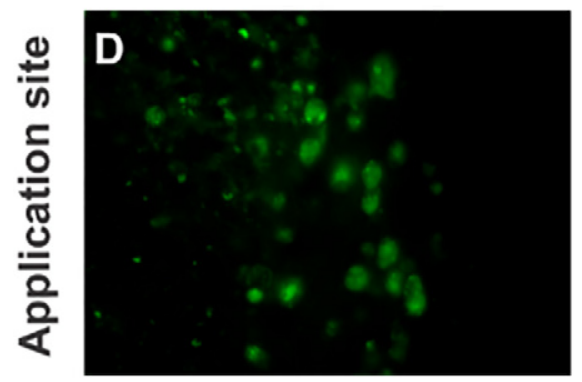

BDNF

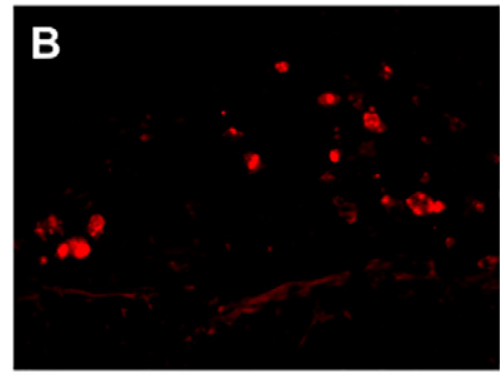

GDNF

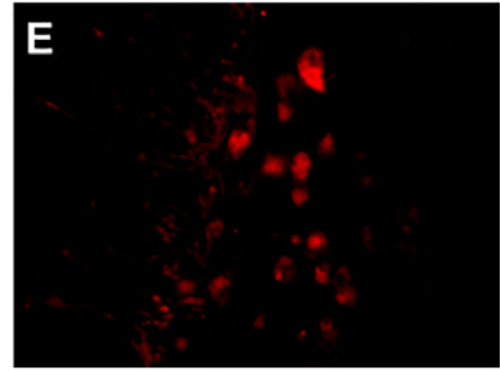

MERGE

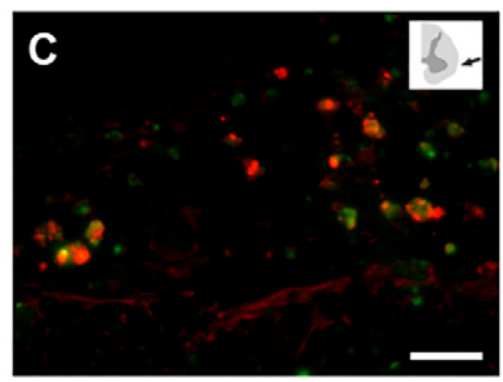

MERGE

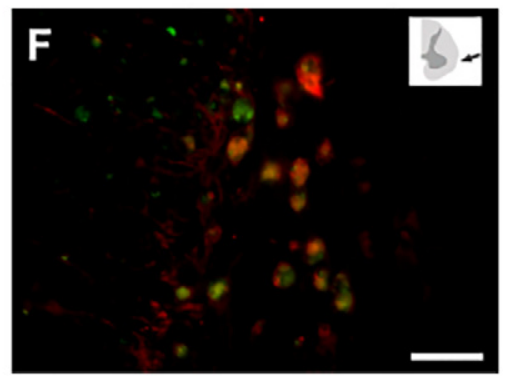

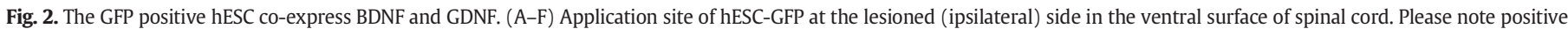
immunostaining anti-BDNF and anti-GDNF (red) in GFP positive hESC, 2 weeks after cell engraftment. Scale bar $=50 \mu \mathrm{m}$.

non-injured (contralateral) side showed only basal labeling of GFAPpositive astrocytic processes nearby large motoneurons. On the contrary, at the ipsilateral side, a significant increase in astrocyte reactivity after VRA was observed. Such increase of GFAP was particularly concentrated around the avulsed neurons. However, the animals which received treatments showed a significantly less intense astroglial reactivity when compared with the two control groups (animals which received only the fibrin sealant and only the fibrin sealant plus doxycycline) (Fig. 5). Quantitative assessment was carried out by calculating the percentage ratio of the integrated pixels density between the ipsilateral versus the contralateral sides of each animal: AV + FS: $177.5 \%$ \pm 4.13\%; AV + FS + hESC + DOX: $127.4 \% \pm 1.78 \%$; AV + FS + DOX: $176.7 \% \pm 3.89 \%$; AV + FS + hESC: $150.8 \% \pm 6.07 \%$; AV + FS + FGF2: $158.5 \% \pm 4.68 \%$; $n=5$ per group (Fig. 5 ). Importantly, a significantly reduced GFAP staining was observed in the lesioned side following hESC + DOX treatment, indicating that the stem cells overexpressing FGF2 can substantially reduce the degree of astrogliosis. Moreover, the direct application of the recombinant FGF2 also significantly reduced astrogliosis. Of note, the non-induced cells (AV + FS + hESC, without doxycycline) also led to reduced astrogliosis, which partially corroborates the results obtained with the BDNF and GDNF immunolabeling (Fig. 2), and further demonstrates that the engrafted hESCs can elicit their positive effects via various neurotrophic factors in vivo.

Staining was performed with Iba 1 antiserum to evaluate microglial reactivity. Hypertrophic microglial cells were observed ipsilateral to lesion, especially in close contact with avulsed motoneurons (Fig. 6). Nevertheless, quantification of immunolabeling, calculated by the percentage ratio of the integrated density of pixels between ipsi- and contralateral sides, showed no statistically significant differences among the groups, while the treatment with the induced hESC still showed a trend to reduce the microglial reactivity: AV + FS: $291.9 \% \pm 17.30 \%$; AV + FS + hESC + DOX: 258.2\% \pm 19.77\%; AV + FS + DOX: $328.6 \% \pm 10.71 \%$; AV + FS + hESC: $306.8 \% \pm 17.13 \%$; AV + FS + FGF2: $291.1 \% \pm 29.55 \%$; $n=5$ per group (Fig. 6). Overall, these results suggest that hESC and FGF2 can be used to support neuroprotection in vivo due to their immunomodulatory properties. However, the precise regimens of the treatments still require additional studies.

\subsection{FGF2 gene expression in hESC}

Quantitative RT-PCR was carried out to demonstrate FGF2 overexpression in transgenic hESCs induced with doxycycline in vitro. Thus, Fig. 7A represents normalized quantification of FGF2 obtained in arbitrary units. The degree of transcription of the FGF2 gene was about two orders of magnitude higher in the induced hESCs compared to the non-induced and the wild-type counterparts. This demonstrates that the stem cells can be bioengineered in order to obtain stem cell lines with properties needed for efficient neuroprotection.

\section{7. $\beta 2$-Microglobulin ( $\beta 2 m)$ and cytokines (TNF $\alpha$, IL-6, IL-10, IL-1 $\beta$ ) gene expression}

RT-qPCR analysis showed increased $\beta 2 \mathrm{~m}$ gene transcript levels in all lesion and treatment groups in comparison to the uninjured control. Furthermore, FGF2 treated group displayed the highest $\beta 2 \mathrm{~m}$ mRNA levels. Quantitative data and statistical comparisons are presented in Fig. 7B (AV + FS: $2.72 \pm 0.32$; AV + FS + hESC + DOX: $3.31 \pm 0.26$; $\mathrm{AV}+\mathrm{FS}+\mathrm{DOX}: 2.53 \pm 0.32 ; \mathrm{AV}+\mathrm{FS}+\mathrm{hESC}: 3.33 \pm 0.08 ; \mathrm{AV}+\mathrm{FS}$ + FGF2: $4.50 \pm 0.66 ; \mathrm{n}=5$ per group).

TNF $\alpha$ mRNA expression significantly increased in all treated groups, except following cell therapy in combination with doxycycline administration (AV + FS + hESC + DOX, induced cells), which presented the lowest values which did not statistically differ from the control (TNF $\alpha$ : AV + FS: $1.87 \pm 0.14 ;$ AV + FS + hESC + DOX: $1.19 \pm 0.05$; AV + FS + DOX: $1.94 \pm 0.15 ;$ AV + FS + hESC: $1.64 \pm 0.21 ;$ AV + FS + FGF2: $1.63 \pm 0.11 ; n=5$ per group) (Fig. $7 C$ ).

IL10 transcript levels increased significantly post injury in all treated groups, as compared to unlesioned rats. The upregulation was the highest when hESCs were employed (AV + FS: $12.42 \pm 2.33$; AV + FS + hESC + DOX: 20,33 \pm 4,17; AV + FS + DOX: 13,97 $\pm 2,25 ;$ AV + FS + hESC: $19,71 \pm 4,17 ;$ AV + FS + FGF2: $14,33 \pm 1,57 ; n=5$ per group) (Fig. 7D). Notably, the FGF2 did not lead to any visible effect on the expression of IL10 neither in the case of the induced cells, nor upon direct delivery of rFGF2. 

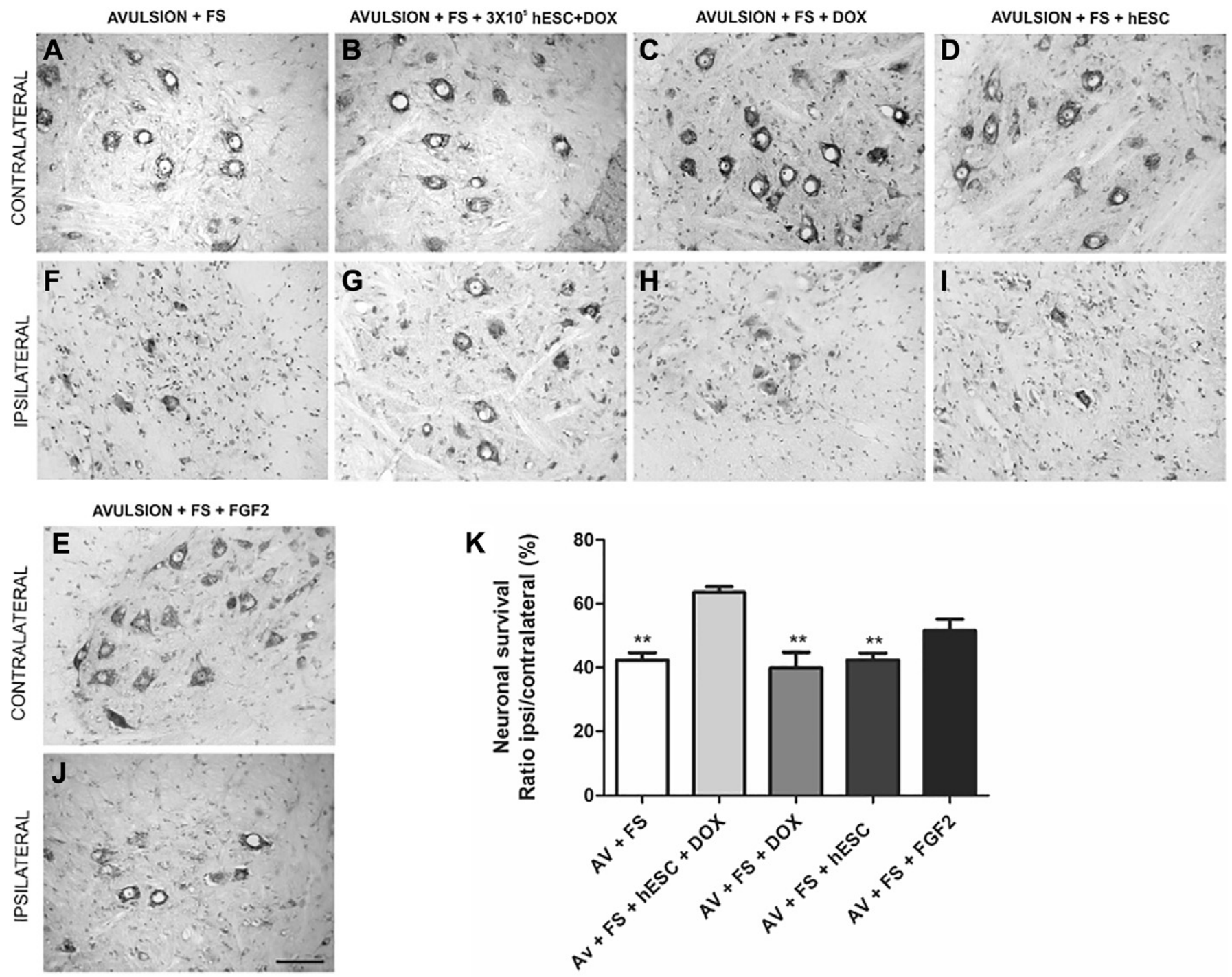

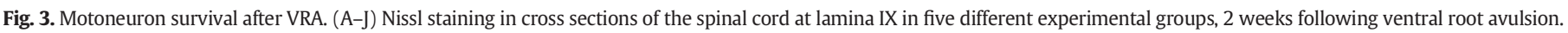

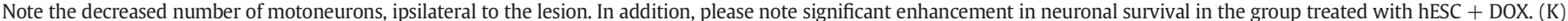

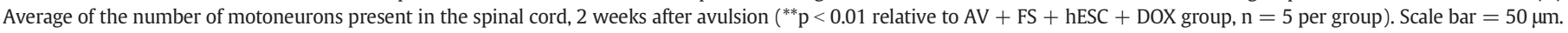
Mean \pm SE. AV: avulsion; FS: fibrin sealant; hESC: human embryonic stem cells; DOX: doxycycline.

In line with changes described above, the mRNA levels of the pro-inflammatory cytokines IL1 $\beta$ and IL-6 were also significantly increased in all injured and treated groups. Of note, the hESCs therapy did not show any differences for neither gene (IL-6: AV + FS $2.39 \pm 0.34$; AV + FS + hESC + DOX: $2.04 \pm 0.14 ;$ AV + FS + DOX: $2.69 \pm 0.11 ;$ AV + FS + hESC: $2.45 \pm 0.41 ;$ AV + FS + FGF2: $3.12 \pm 0.47$. IL1ß: AV + FS: $5.96 \pm 0.89 ;$ AV + FS + hESC + DOX: $6.43 \pm 1.08 ;$ AV + FS + DOX: $5.87 \pm 1.03 ; \mathrm{AV}+\mathrm{FS}+\mathrm{hESC}: 6.11 \pm 1.11 ; \mathrm{AV}+\mathrm{FS}+\mathrm{FGF} 2: 8.44 \pm$ $2.09 ; \mathrm{n}=5$ per group) (Fig. 7E and $\mathrm{F}$ ). Interestingly, the direct treatment with rFGF2 led to increased expression of both IL1 $\beta$ and IL- 6 cytokines. This might have to do with a complex dynamics of interplay between the stem cells and the growth factors during the process of healing after neuronal injury.

\section{Discussion}

Several studies have explored the potential of cell therapies to treat diseases and injuries in the CNS (Lukovic et al., 2014; Osaka et al., 2010; Parr et al., 2008). Likewise, many studies have approached the use of neurotrophic factors for therapies (Bergerot et al., 2004; Pajenda et al., 2014). Providing neurotrophic substances to patients with a spinal cord injury may be an option to transiently rescue axotomized neurons while reconnection with the target organ is being restored. In this context, the use of fibroblast growth factor-2 has shown promising results (Goldshmit et al., 2014; Shaimardanova et al., 2012). Consequently, the present study aimed at possible alternatives to recover injured motoneurons using, for the first time to the best of our knowledge, cell therapy with human embryonic stem cells modified to overexpress FGF2. We particularly addressed stem cells to investigate possibilities of future cell replacement following neurodegeneration. However, based on the fact that such cell replacement therapy, most probably, is not achievable in the nearest future, the possibility of a temporal trophic support still holds potential for therapeutic applications (Brown et al., 1993; Dvorak et al., 2006; Eiselleova et al., 2009; Holubcova et al., 2011). Another concern with using hESC is teratoma formation (Kunova et al., 2013). However, in the present study we did not observe any tumors during the twoweek engraftment period. On the contrary, hESC seemed integrated to the tissue, migrating towards the spinal cord motor nucleus (Rexed's lamina IX).

Our results show that the group which received the administration of hESC, induced by doxycycline to overexpress FGF2, displayed survival of a significant number of motoneurons when compared to the other 

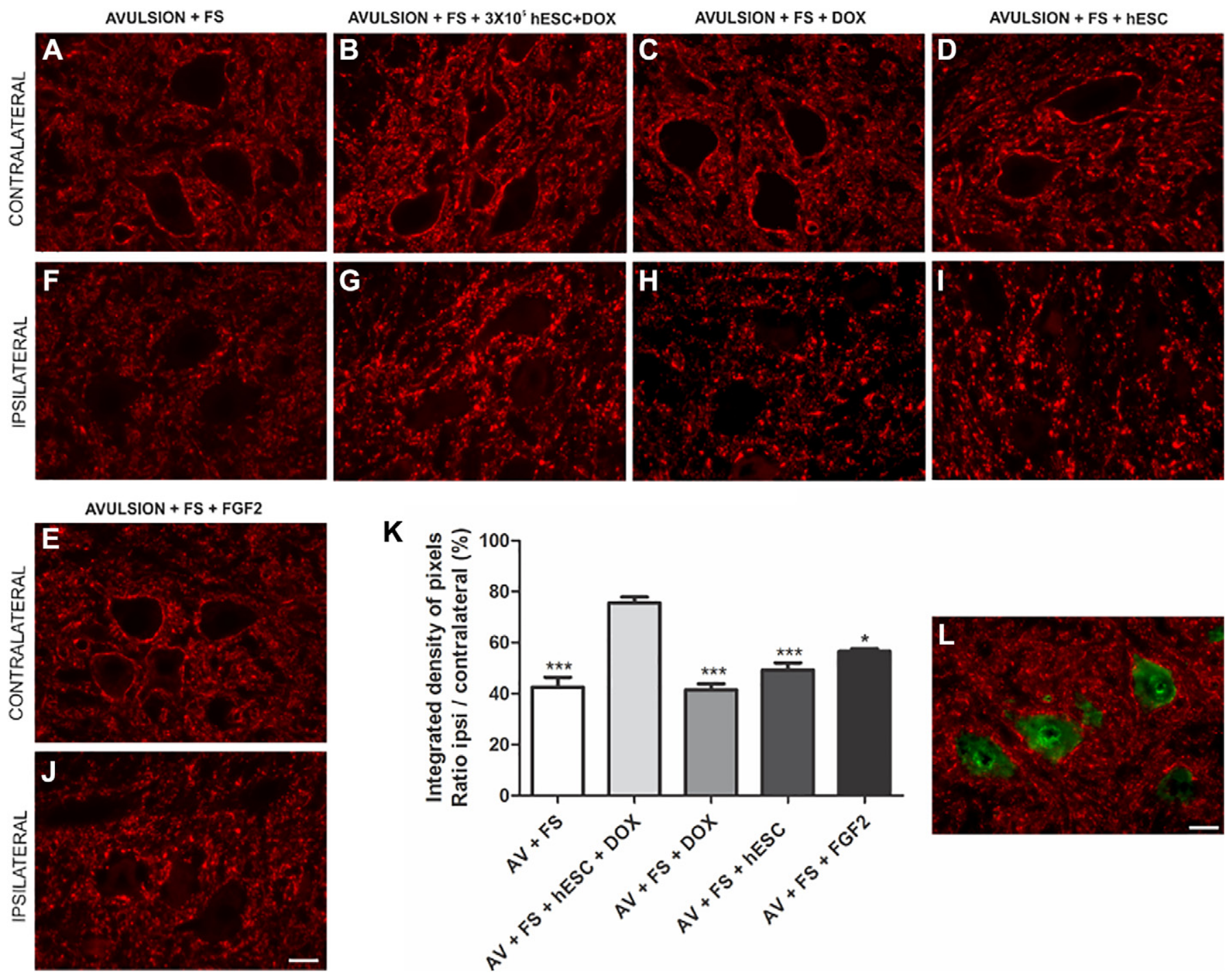

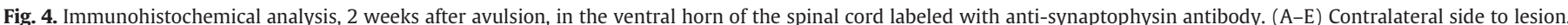

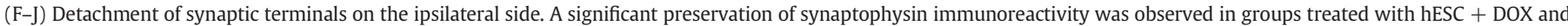

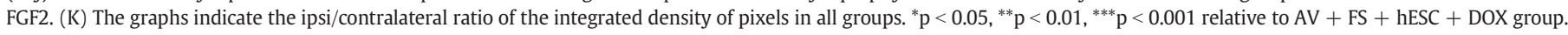

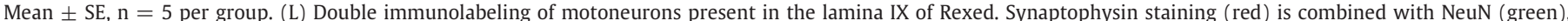

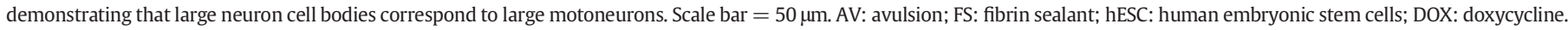

groups. We concluded that the hESC elicited a neuroprotective effect, which supported viability of the axotomized neurons during the wellknown two-week post injury critical acute phase (Koliatsos et al., 1994).

Experimental studies revealed that one single application of exogenous FGF2 promotes long-term survival of intermediate-lateral motoneurons in the spinal cord ventral horn. However, any appropriate function recovery could not the achieved, indicating that FGF does not contribute to regeneration itself (Chu and Wu, 2009; Teng et al., 1998). In a different manner, a study conducted by Liu et al. showed that mesenchymal stem cells, derived from bone marrow and modified to express FGF2, effectively promoted axonal regeneration and motor function. The cells were transplanted to the site of spinal cord injury in rats (Liu et al., 2011). This divergence of results may be due to FGF2 exposure time in the injured spinal cord, since transgenic cells may be capable of secreting the growth factor over a longer period of time. In line with this, our present results show that treatment with exogenous rFGF2 results in a longlasting neuronal survival, although weaker than achieved with the induced hESC. According to Pajenda et al., neurotrophic factors are important elements in prevention of neuronal degeneration (Pajenda et al., 2014). Obviously, the patterns of expression of these factors and its dynamics can play a role as well. Neuronal factors can also stimulate axonal growth towards PNS, leading to ventral root re-innervation.

Importantly, in the present study, production of BDNF and GDNF by induced hESC at the injury site was observed. This may in turn contribute to the decrease of nitric oxide synthase (NOS) activity, which plays crucial role in initiating degeneration of spinal motoneurons after avulsion (Ruan et al., 1995; Sakamoto et al., 2003; Watabe et al., 2005). It is known that the FGF2 has a very complex, rather generalized effect on the homeostasis of hESC (Dvorak et al., 2006). Therefore, its overexpression can well cause induction of other genes. The fact that the exogenously added rFGF also elicited neuroprotective effect suggests, however, that the induced hESC contributed to neuroprotection at least partially directly via FGF2. The specific contribution of the FGF2 alone or in combination with other factors, like BDNF and GDNF, will be among the subjects of our further studies.

One important issue addressed herein refers to synaptic plasticity after treatment with induced hESCs (hESC + DOX) and exogenous recombinant FGF2. After ventral root avulsion, disconnection between motoneurons and muscle fibers occurs, and one of the most prominent reactions is the extensive detachment of presynaptic terminals from soma and dendrites (Brännström and Kellerth, 1998). The axotomized 

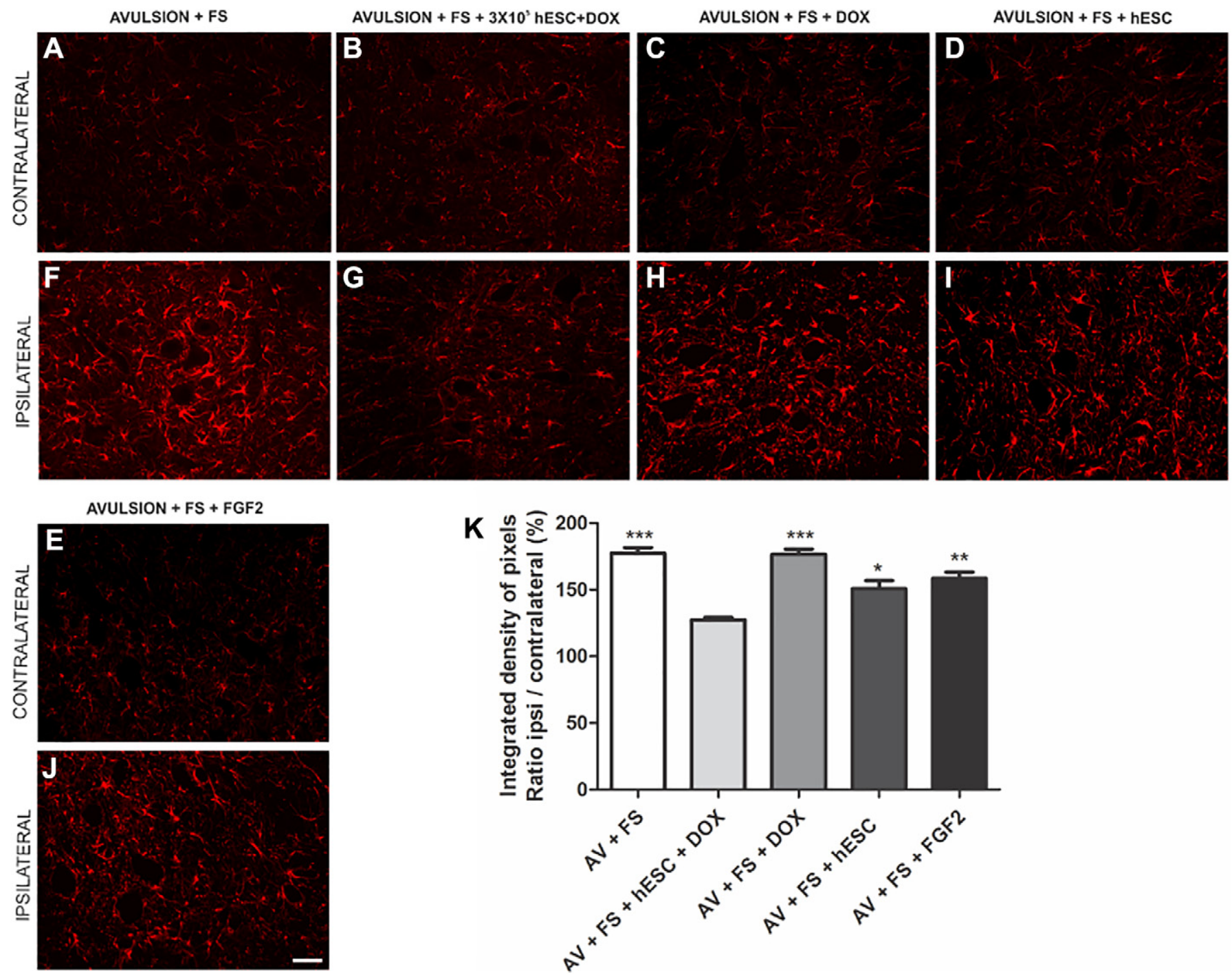

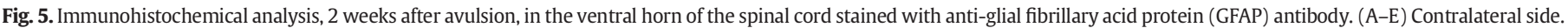

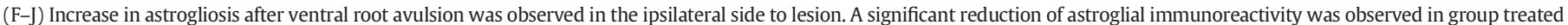

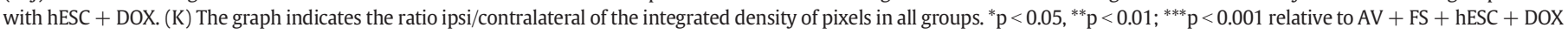
group. Scale bar $=50 \mu \mathrm{m}$. Mean $\pm \mathrm{SE}, \mathrm{n}=5$ per group. AV: avulsion; FS: fibrin sealant; hESC: human embryonic stem cells; DOX: doxycycline.

neurons show significant loss of inputs, lowering or even abolishing synaptic transmission (Delgado-Garcia et al., 1988; Takata and Nagahama, 1983). This is in line with upregulation of $\beta 2 \mathrm{~m}$ described herein, since $\beta 2 \mathrm{~m}$ is a subunit of MHCI, while upregulation of the MHC I has been implicated in synapse retraction and input size adjustments during development and after lesions (Huh et al., 2000; Oliveira et al., 2004).

In our study, therapy with the induced hESC, besides promoting the survival of avulsed motoneurons, also reduced loss of synaptic inputs (synaptic stripping). Thus, increased synaptophysin immunolabeling indicated that both groups of animals, which received either the FGF2 overexpressing cells or exogenous rFGF2, showed significant input preservation up to two weeks after injury. One possibility to be considered here is that treatment with the induced hESCs also inhibited astroglial reaction. This can directly contribute to synaptic preservation, as astrogliosis is associated with retraction of pre-synaptic terminals to axotomized motoneurons (Aldskogius and Kozlova, 1998). Astrocytes and microglia act effectively in the maintenance of homeostasis necessary to synaptic transmission and plasticity (Aldskogius and Kozlova, 1998; Araque and Perea, 2004). In this way, co-cultures of neurons and astrocytes revealed a greatly reduced number of synaptic contacts when neurons were cultured with the reactivated astrocytes (Emirandetti et al., 2006). Thus, the attenuation of the reactive astrogliosis can be one of the mechanisms involved in the reduction of the synaptic elimination observed following cell therapy and FGF2 administration.

In vitro studies have highlighted the importance of FGF2 to mediate glial responses in response to injuries (Di Pucchio et al., 1996; Hou et al., 1995). Herein, the group treated with hESCs overexpressing FGF2 exhibited the lowest GFAP immunoreactivity ipsilateral to lesion, in line with previous in vitro study (Reilly et al., 1998). Reduction of GFAP expression is probably connected to the presence of FGF receptors on the surface of astrocytes, since Kang et al. demonstrated that deletion of FGFR results in intense astrogliosis (Kang et al., 2014). Data reported by Goldshmit et al. also demonstrated that injection of FGF2 after spinal cord hemi-section significantly decreases GFAP immunoreactivity in astrocytes present at the lesion epicenter (Goldshmit et al., 2014).

There is an understanding that inflammation can have both beneficial and damaging effects to neurons after trauma. On one hand, it causes generalized cellular damage and degradation of the extracellular matrix (Praticò and Sung, 2004; Sinescu et al., 2010). On the other hand, it may benefit neuronal regeneration and functional recovery. Indeed, the activated macrophages and microglia can play important roles by phagocytizing damaged and degenerating elements (Greenhalgh and David, 2014). In the present study, VRA increased mRNA gene transcripts for IL-1 $\beta$ in all injured groups. Considering the results obtained 

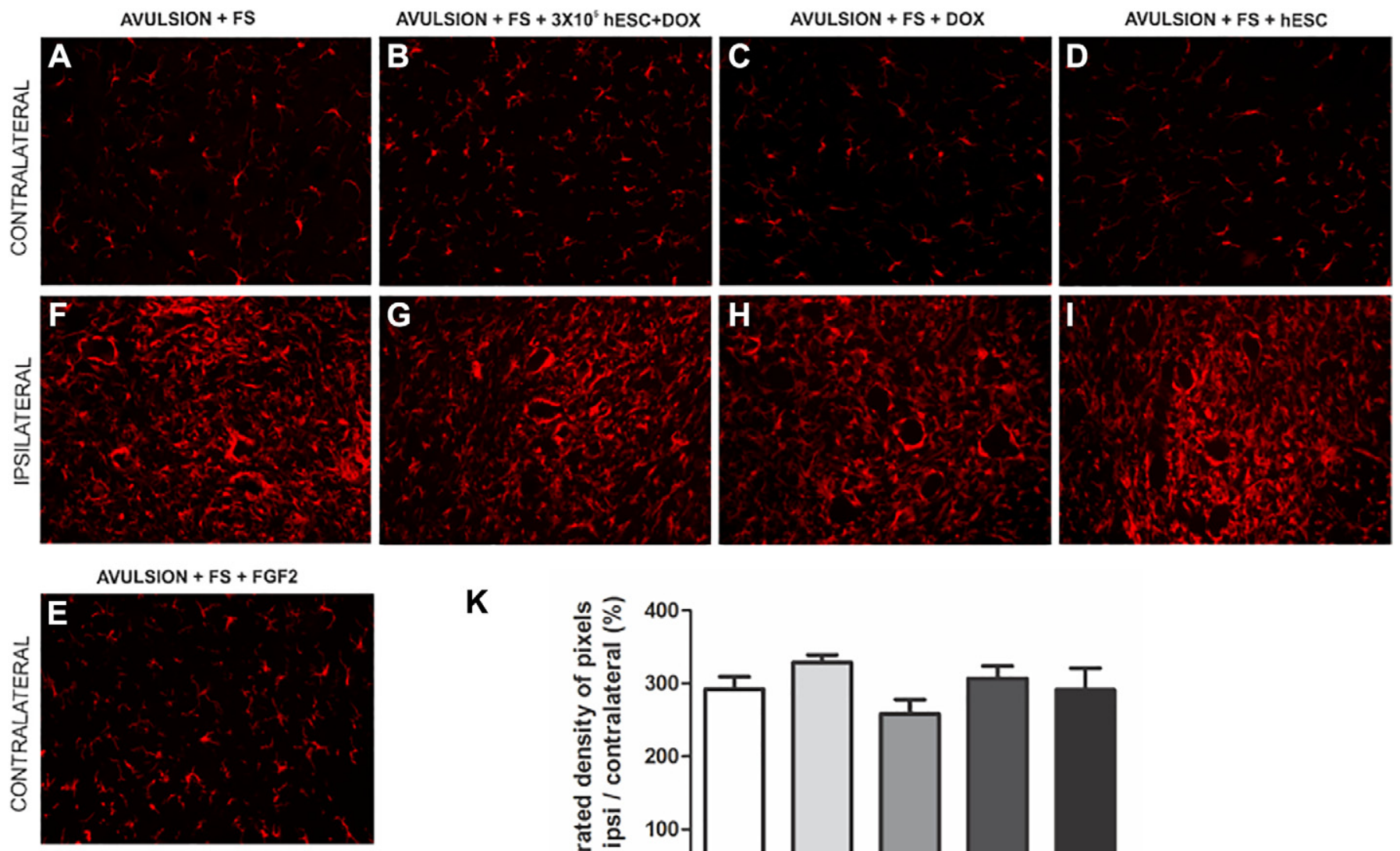

\section{$\mathbf{K}$}

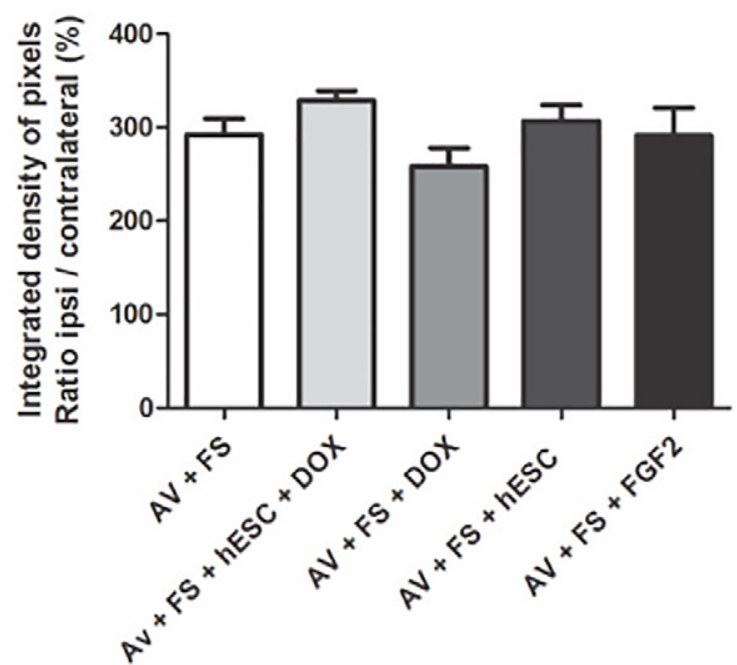

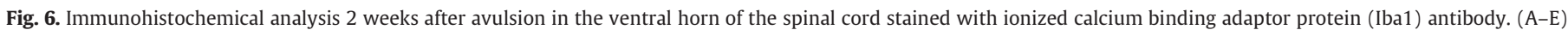

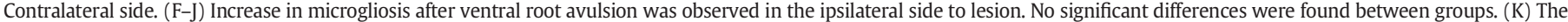

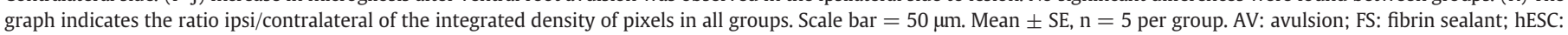
human embryonic stem cells; DOX: doxycycline.

by Han et al., where the peak of IL-1 $\beta$ upregulation was three days after injury (Han et al., 2015), it is possible that the grafted hESCs led to early modulation of IL- $1 \beta$ expression. In line with this, TNF- $\alpha$ increased in all lesioned groups except in that treated with induced hESC. Our result corroborates the study by Goldshmit et al. in which FGF2, subcutaneously administered after spinal cord hemisection, led to decrease of TNF- $\alpha$ expression at the site of injury (Goldshmit et al., 2014). In addition, it was observed that TNF- $\alpha$ plays a role in regulating microglial and astroglial reactivity and proliferation (Tzeng et al., 1999). In turn, in our study the group treated with the induced hESCs overexpressing FGF2 displayed the lowest expression of TNF- $\alpha$, coupled with significant reduction of astroglial reactivity.

Among the anti-inflammatory cytokines, interleukin-10 (IL-10) is one of the most efficient to decrease TNF- $\alpha$ production after spinal cord injury, which can also reduce astrocyte and microglia reactiveness (Bethea et al., 1999; Crisi et al., 1995; Plunkett et al., 2001). IL-10 is thus neuroprotective, allowing enhanced functional recovery after spinal cord injury (David et al., 2012). In our study, IL-10 expression showed a trend to increase in both groups treated with the cells compared to other injured groups. This is in concordance with previous studies demonstrating that IL-10 attenuated production of pro-inflammatory cytokines, such as IL-1 $\beta$, TNF- $\alpha$ and IL-6 (Balasingam and Yong, 1996; Fiorentino et al., 1991; Plunkett et al., 2001).

\section{Conclusion}

In summary, our results show that transgenic hESC, overexpressing FGF2 in an inducible manner, promote neuroprotective effects in the spinal cord after ventral root avulsion. This effect is achievable possibly through the modulation of pro-inflammatory cytokines, such as TNF- $\alpha$ in combination with early expression of BDNF and GDNF. Overall, such pro-regenerative modulation results in substantial synaptic preservation and motoneuron survival, in addition to attenuation of astroglial reactivity.

\section{Author contributions}

Marta Rocha Araújo: Conception and design, collection and/or assembly of data, data analysis and interpretation, manuscript writing.

Sergiy Kyrylenko: Provision of study material or patients, collection and/or assembly of data, manuscript writing.

Aline Barroso Spejo: Collection and/or assembly of data. 
A

FGF2

(in vitro)

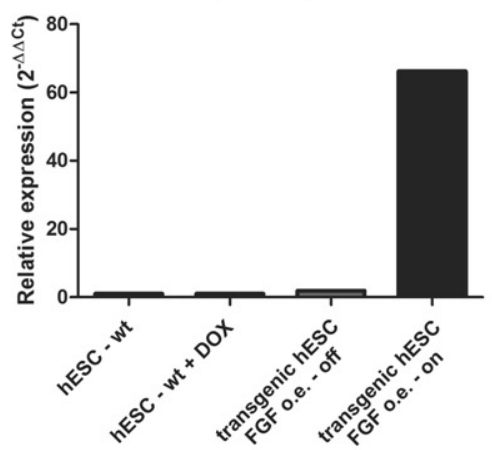

C

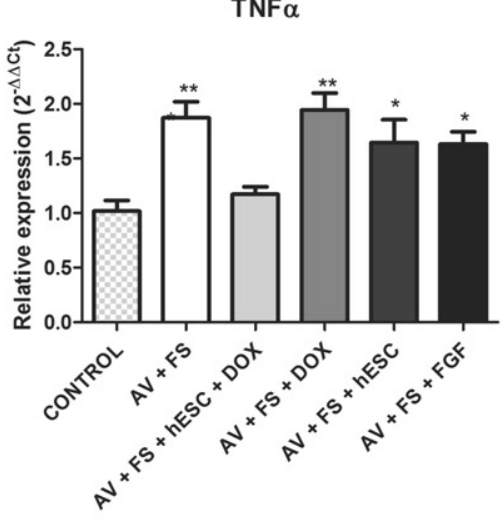

E

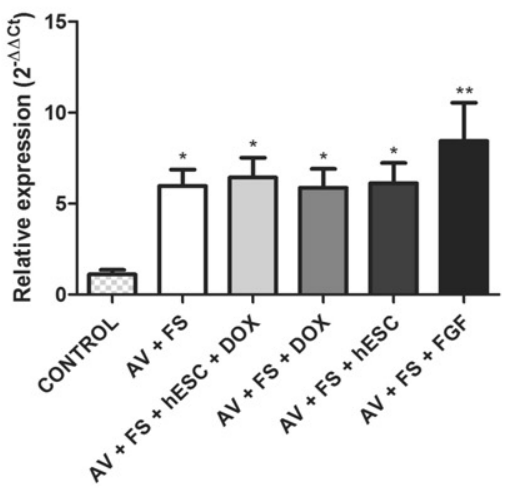

B

32-microglobulin

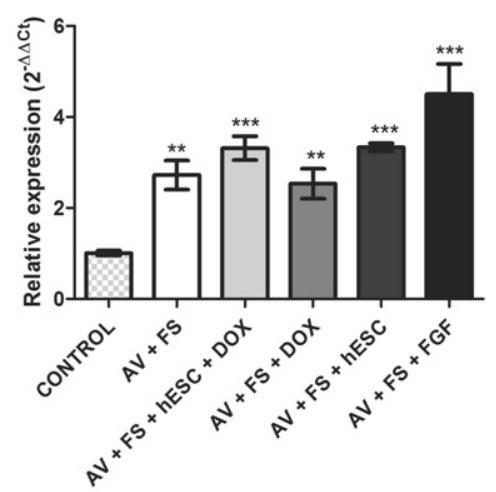

IL10

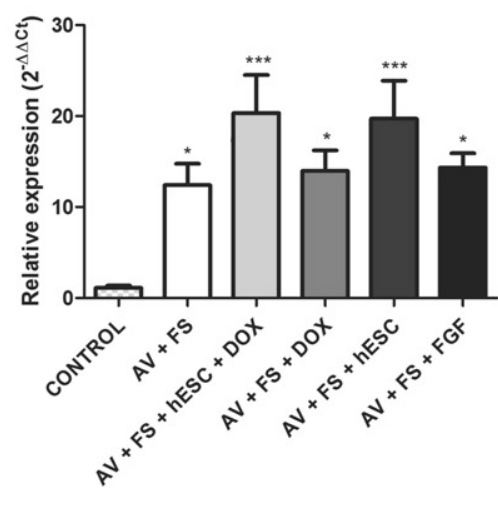

$\mathbf{F}$

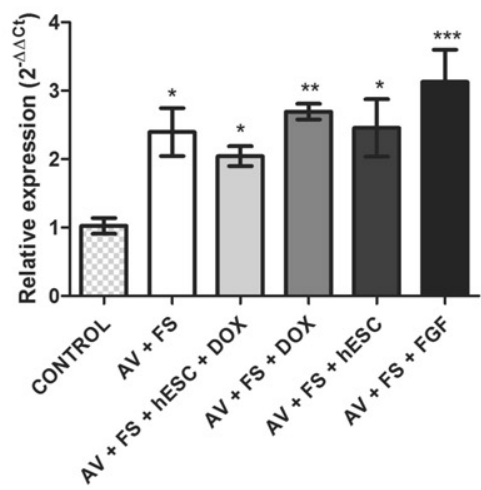

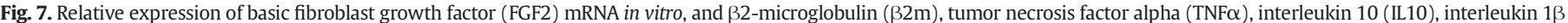

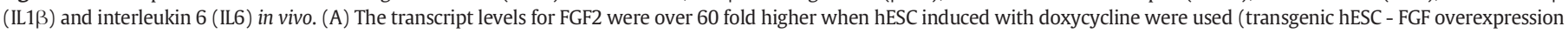

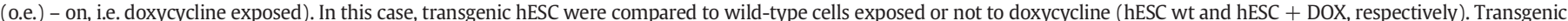

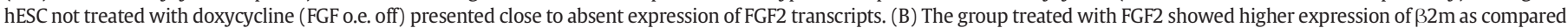

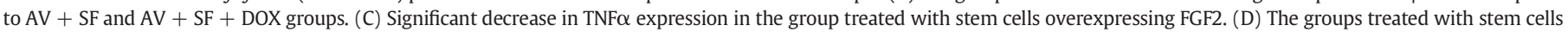

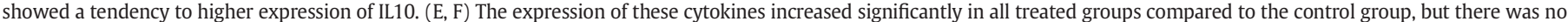

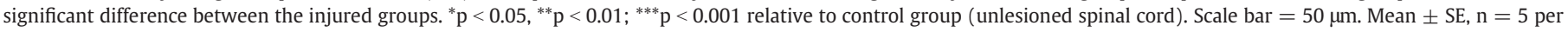
group. AV: avulsion; FS: fibrin sealant; hESC: human embryonic stem cells; DOX: doxycycline.

Mateus Vidigal de Castro: Collection and/or assembly of data.

Rui Seabra Ferreira Junior: Provision of study material or patients.

Benedito Barraviera: Provision of study material or patients.

Alexandre Leite Rodrigues de Oliveira: Conception and design, data analysis and interpretation, manuscript writing, final approval of manuscript.

\section{Conflicts of interest}

The authors declare no conflict of interest.

\section{Acknowledgments}

The authors are thankful to São Paulo Research Foundation (FAPESP) for providing financial support (2012/20456-6; 2013/22045-6; 2013/ $23030-2 ; 2014 / 06892-3$ ) and to the National Council for Scientific and Technological Development (CNPq; 300553/2013-9). This work also received a financial contribution from the European Community within the Seventh Framework Programme (FP/2007-2013) under Grant Agreement No. 229603 co-financed by the South Moravian Region of Czech Republic within the SoMoPro programme [to SK]. Special thanks 
are also extended to the Centre for the Study of Venoms and Venomous Animals, CEVAP at São Paulo State University, UNESP, Brazil; Dr. Anja Weise from Institut für Humangenet und Anthropologie, University of Jena, Germany for karyotyping the stem cells.

\section{Appendix A. Supplementary data}

Supplementary data to this article can be found online at http://dx. doi.org/10.1016/j.expneurol.2017.04.009.

\section{References}

Aldskogius, H., Kozlova, E.N., 1998. Central neuron-glial and glial-glial interactions following axon injury. Prog. Neurobiol. 55, 1-26.

Araque, A., Perea, G., 2004. Glial modulation of synaptic transmission in culture. Glia 47 241-248.

Balasingam, V., Yong, V.W., 1996. Attenuation of astroglial reactivity by interleukin-10. J. Neurosci. 16, 2945-2955.

Barros, L.C., Ferreira Junior, R.S., Barraviera, S.R., Stolf, H.O., Thomazinni-Santos, I.A., Mendes-Giannini, M.J., Toscano, E., Barraviera, B., 2009. A new fibrin sealant from Crotalus durissus terrificus venom: applications in medicine. J. Toxicol. Environ. Health B, Crit. Rev. 12 (8), 8.

Barros, L.C., Soares, A.M., Costa, F.L., Rodrigues, V.M., Fuly, A.L., Giglio, J.R., Gallacci, M., Thomazini-Santos, I.A., Barraviera, S.R.C.S., Barraviera, B., Ferreira Junior, R.S., 2011 Biochemical and biological evaluation of gyroxin isolated from Crotalus durissus terrifius venom. J. Venomous Anim. Toxins Incl. Trop. Dis. 17, 10.

Bergerot, A., Shortland, P.J., Anand, P., Hunt, S.P., Carlstedt, T., 2004. Co-treatment with riluzole and GDNF is necessary for functional recovery after ventral root avulsion injury. Exp. Neurol. 187, 359-366.

Bethea, J.R., Nagashima, H., Acosta, M.C., Briceno, C., Gomez, F., Marcillo, A.E., Loor, K., Green, J., Dietrich, W.D., 1999. Systemically administered interleukin-10 reduces tumor necrosis factor-alpha production and significantly improves functional recovery following traumatic spinal cord injury in rats. J. Neurotrauma 16, 851-863.

Biscola, N.P., Cartarozzi, L.P., Ulian-Benitez, S., Barbizan, R., Castro, M.V., Spejo, A.B., Ferreira Jr., R.S., Barraviera, B., Oliveira, A.L.R., 2017. Multiple uses of fibrin sealant for nervous system treatment following injury and disease. J. Venomous Anim. Toxins Incl. Trop. Dis. 23, 13.

Brännström, T., Kellerth, J.O., 1998. Changes in synaptology of adult cat spinal alpha-motoneurons after axotomy. Exp. Brain Res. 118, 1-13.

Brown, L.F., Lanir, N., McDonagh, J., Tognazzi, K., Dvorak, A.M., Dvorak, H.F., 1993. Fibroblast migration in fibrin gel matrices. Am. J. Pathol. 142, 273-283.

Carlstedt, T., 2008. Root repair review: basic science background and clinical outcome. Restor. Neurol. Neurosci. 26, 225-241.

Carlstedt, T., 2009. Nerve root replantation. Neurosurg. Clin. N. Am. 20 (39-50), vi.

Cawthorne, C., Swindell, R., Stratford, I.J., Dive, C., Welman, A., 2007. Comparison of doxycycline delivery methods for Tet-inducible gene expression in a subcutaneous xenograft model. J. Biomol. Tech. 18, 120-123.

Chu, T.H., Wu, W., 2009. Neurotrophic factor treatment after spinal root avulsion injury. Cent. Nerv. Syst. Agents Med. Chem. 9, 40-55.

Crisi, G.M., Santambrogio, L., Hochwald, G.M., Smith, S.R., Carlino, J.A., Thorbecke, G.J., 1995. Staphylococcal enterotoxin B and tumor-necrosis factor-alpha-induced relapses of experimental allergic encephalomyelitis: protection by transforming growth factor-beta and interleukin-10. Eur. J. Immunol. 25, 3035-3040.

David, S., López-Vales, R., Wee Yong, V., 2012. Harmful and beneficial effects of inflammation after spinal cord injury: potential therapeutic implications. Handb. Clin. Neurol. 109, 485-502.

Delgado-Garcia, J.M., Del Pozo, F., Spencer, R.F., Baker, R., 1988. Behavior of neurons in the abducens nucleus of the alert cat-III. Axotomized motoneurons. Neuroscience 24, 143-160.

Di Pucchio, T., Ennas, M.G., Presta, M., Lauro, G.M., 1996. Basic fibroblast growth factor modulates in vitro differentiation of human fetal microglia. Neuroreport 7, 2813-2817.

Dono, R., 2003. Fibroblast growth factors as regulators of central nervous system development and function. Am. J. Phys. Regul. Integr. Comp. Phys. 284, R867-R881.

Dvorak, P., Dvorakova, D., Hampl, A., 2006. Fibroblast growth factor signaling in embryonic and cancer stem cells. FEBS Lett. 580, 2869-2874.

Eckenstein, F.P., 1994. Fibroblast growth factors in the nervous system. J. Neurobiol. 25, 1467-1480.

Eiselleova, L., Matulka, K., Kriz, V., Kunova, M., Schmidtova, Z., Neradil, J., Tichy, B. Dvorakova, D., Pospisilova, S., Hampl, A., Dvorak, P., 2009. A complex role for FGF-2 in self-renewal, survival, and adhesion of human embryonic stem cells. Stem Cells 27, 1847-1857.

Emirandetti, A., Graciele Zanon, R., Sabha, M., de Oliveira, A.L., 2006. Astrocyte reactivity influences the number of presynaptic terminals apposed to spinal motoneurons after axotomy. Brain Res. 1095, 35-42.

Evans, M.J., Kaufman, M.H., 1981. Establishment in culture of pluripotential cells from mouse embryos. Nature 292, 154-156.

Fawcett, J.W., Asher, R.A., 1999. The glial scar and central nervous system repair. Brain Res. Bull. 49, 377-391.

Ferreira Jr., R.S., de Barros, L.C., Abbade, L.P.F., Barraviera, S., Silvares, M.R.C., de Pontes, L.G., Dos Santos, L.D., Barraviera, B., 2017. Heterologous fibrin sealant derived from snake venom: from bench to bedside - an overview. J. Venomous Anim. Toxins Incl. Trop. Dis. 23, 21.
Fiorentino, D.F., Zlotnik, A., Mosmann, T.R., Howard, M., O'Garra, A., 1991. IL-10 inhibits cytokine production by activated macrophages. J. Immunol. 147, 3815-3822.

Follesa, P., Wrathall, J.R., Mocchetti, I., 1994. Increased basic fibroblast growth factor mRNA following contusive spinal cord injury. Brain Res. Mol. Brain Res. 22, 1-8.

Freria, C.M., Zanon, R.G., Santos, L.M., Oliveira, A.L., 2010. Major histocompatibility complex class I expression and glial reaction influence spinal motoneuron synaptic plasticity during the course of experimental autoimmune encephalomyelitis. J. Comp. Neurol. 518, 990-1007.

Goldshmit, Y., Frisca, F., Pinto, A.R., Pébay, A., Tang, J.K., Siegel, A.L., Kaslin, J., Currie, P.D. 2014. Fgf2 improves functional recovery-decreasing gliosis and increasing radial glia and neural progenitor cells after spinal cord injury. Brain Behav. 4, 187-200.

Gómez-Pinilla, F., Lee, J.W., Cotman, C.W., 1992. Basic FGF in adult rat brain: cellular distribution and response to entorhinal lesion and fimbria-fornix transection. J. Neurosci. $12,345-355$.

Greenhalgh, A.D. David, S., 2014. Differences in the phagocytic response of microglia and peripheral macrophages after spinal cord injury and its effects on cell death. J. Neurosci. 34, 6316-6322.

Han, D., Wu, C., Xiong, Q., Zhou, L., Tian, Y., 2015. Anti-inflammatory mechanism of bone marrow mesenchymal stem cell transplantation in rat model of spinal cord injury. Cell Biochem. Biophys. 71, 1341-1347.

He, J.W., Hirata, K., Kuraoka, A., Kawabuchi, M., 2000. An improved method for avulsion of lumbar nerve roots as an experimental model of nitric oxide-mediated neuronal degeneration. Brain Res. Brain Res. Protoc. 5, 223-230.

Holubcova, Z., Matula, P., Sedlackova, M., Vinarsky, V., Dolezalova, D., Barta, T., Dvorak, P., Hampl, A., 2011. Human embryonic stem cells suffer from centrosomal amplification. Stem Cells 29, 46-56.

Hou, Y.J., Yu, A.C., Garcia, J.M., Aotaki-Keen, A., Lee, Y.L., Eng, L.F., Hjelmeland, L.J., Menon, V.K., 1995. Astrogliosis in culture. IV. Effects of basic fibroblast growth factor J. Neurosci. Res. 40, 359-370.

Huh, G.S., Boulanger, L.M., Du, H., Riquelme, P.A., Brotz, T.M., Shatz, C.J., 2000. Functional requirement for class I MHC in CNS development and plasticity. Science 290 2155-2159.

Ishiyama, J., Saito, H., Abe, K., 1991. Epidermal growth factor and basic fibroblast growth factor promote the generation of long-term potentiation in the dentate gyrus of anaesthetized rats. Neurosci. Res. 12, 403-411.

Kang, W., Balordi, F., Su, N., Chen, L., Fishell, G., Hébert, J.M., 2014. Astrocyte activation is suppressed in both normal and injured brain by FGF signaling. Proc. Natl. Acad. Sci. U. S. A. 111, E2987-E2995.

Kishino, A., Ishige, Y., Tatsuno, T., Nakayama, C., Noguchi, H., 1997. BDNF prevents and reverses adult rat motor neuron degeneration and induces axonal outgrowth. Exp. Neurol. 144, 273-286.

Koliatsos, V.E., Price, W.L., Pardo, C.A., Price, D.L., 1994. Ventral root avulsion: an experimental model of death of adult motor neurons. J. Comp. Neurol. 342, 35-44.

Kunova, M., Matulka, K., Eiselleova, L., Salykin, A., Kubikova, I., Kyrylenko, S., Hampl, A. Dvorak, P., 2013. Adaptation to robust monolayer expansion produces human pluripotent stem cells with improved viability. Stem Cells Transl. Med. 2, 246-254.

Leme, R.J., Chadi, G., 2001. Distant microglial and astroglial activation secondary to experimental spinal cord lesion. Arq. Neuropsiquiatr. 59, 483-492.

Liesi, P., Kauppila, T., 2002. Induction of type IV collagen and other basement-membraneassociated proteins after spinal cord injury of the adult rat may participate in formation of the glial scar. Exp. Neurol. 173, 31-45.

Liu, X., Mashour, G.A., Webster, H.F., Kurtz, A., 1998. Basic FGF and FGF receptor 1 are expressed in microglia during experimental autoimmune encephalomyelitis: temporally distinct expression of midkine and pleiotrophin. Glia 24, 390-397.

Liu, W.G., Wang, Z.Y., Huang, Z.S., 2011. Bone marrow-derived mesenchymal stem cells expressing the bFGF transgene promote axon regeneration and functional recovery after spinal cord injury in rats. Neurol. Res. 33, 686-693.

Livak, K.J., Schmittgen, T.D., 2001. Analysis of relative gene expression data using realtime quantitative PCR and the 2(-Delta Delta C(T)) Method. Methods 25, 402-408.

Livesey, F.J., Fraher, J.P., 1992. Experimental traction injuries of cervical spinal nerve roots: a scanning EM study of rupture patterns in fresh tissue. Neuropathol. Appl. Neurobiol. 18, 376-386.

Lukovic, D., Valdés-Sanchez, L., Sanchez-Vera, I., Moreno-Manzano, V., Stojkovic, M. Bhattacharya, S.S., Erceg, S., 2014. Brief report: astrogliosis promotes functional recovery of completely transected spinal cord following transplantation of hESC-derived oligodendrocyte and motoneuron progenitors. Stem Cells 32, 594-599.

Malessy, M.J., Pondaag, W., van Dijk, J.G., 2009. Electromyography, nerve action potential, and compound motor action potentials in obstetric brachial plexus lesions: validation in the absence of a "gold standard". Neurosurgery 65, A153-A159.

Martens, D.J., Seaberg, R.M., van der Kooy, D., 2002. In vivo infusions of exogenous growth factors into the fourth ventricle of the adult mouse brain increase the proliferation of neural progenitors around the fourth ventricle and the central canal of the spinal cord. Eur. J. Neurosci. 16, 1045-1057.

Mattson, M.P., Scheff, S.W., 1994. Endogenous neuroprotection factors and traumatic brain injury: mechanisms of action and implications for therapy. J. Neurotrauma 11 3-33.

Moore, J.C., Atze, K., Yeung, P.L., Toro-Ramos, A.J., Camarillo, C., Thompson, K., Ricupero, C.L., Brenneman, M.A., Cohen, R.I., Hart, R.P., 2010. Efficient, high-throughput transfection of human embryonic stem cells. Stem Cell Res. Ther. 1, 23.

Novikov, L.N., Novikova, L.N., Holmberg, P., Kellerth, J., 2000. Exogenous brain-derived neurotrophic factor regulates the synaptic composition of axonally lesioned and normal adult rat motoneurons. Neuroscience 100,171-181.

Ohlsson, M., Havton, L.A., 2006. Complement activation after lumbosacral ventral root avulsion injury. Neurosci. Lett. 394, 179-183.

Oliveira, A.L., Langone, F., 2000. GM-1 ganglioside treatment reduces motoneuron death after ventral root avulsion in adult rats. Neurosci. Lett. 293, 131-134. 
Oliveira, A.L., Thams, S., Lidman, O., Piehl, F., Hökfelt, T., Kärre, K., Lindå, H., Cullheim, S., 2004. A role for MHC class I molecules in synaptic plasticity and regeneration of neurons after axotomy. Proc. Natl. Acad. Sci. U. S. A. 101, 17843-17848.

Osaka, M., Honmou, O., Murakami, T., Nonaka, T., Houkin, K., Hamada, H., Kocsis, J.D. 2010. Intravenous administration of mesenchymal stem cells derived from bone marrow after contusive spinal cord injury improves functional outcome. Brain Res. 1343, 226-235.

Ovchinnikov, D.A., Turner, J.P., Titmarsh, D.M., Thakar, N.Y., Sin, D.C., Cooper-White, J.J, Wolvetang, E.J., 2012. Generation of a human embryonic stem cell line stably expressing high levels of the fluorescent protein mCherry. World J. Stem Cells 4, 71-79.

Pajenda, G., Hercher, D., Márton, G., Pajer, K., Feichtinger, G.A., Maléth, J., Redl, H., Nógrádi, A., 2014. Spatiotemporally limited BDNF and GDNF overexpression rescues motoneurons destined to die and induces elongative axon growth. Exp. Neurol. 261, 367-376.

Parr, A.M., Kulbatski, I., Zahir, T., Wang, X., Yue, C., Keating, A., Tator, C.H., 2008 Transplanted adult spinal cord-derived neural stem/progenitor cells promote early functional recovery after rat spinal cord injury. Neuroscience 155, 760-770.

Plunkett, J.A., Yu, C.G., Easton, J.M., Bethea, J.R., Yezierski, R.P., 2001. Effects of interleukin 10 (IL-10) on pain behavior and gene expression following excitotoxic spinal cord injury in the rat. Exp. Neurol. 168, 144-154.

Praticò, D., Sung, S., 2004. Lipid peroxidation and oxidative imbalance: early functional events in Alzheimer's disease. J. Alzheimers Dis. 6, 171-175

Rabchevsky, A.G., Fugaccia, I., Turner, A.F., Blades, D.A., Mattson, M.P., Scheff, S.W., 2000. Basic fibroblast growth factor (bFGF) enhances functional recovery following severe spinal cord injury to the rat. Exp. Neurol. 164, 280-291.

Reilly, J.F., Maher, P.A., Kumari, V.G., 1998. Regulation of astrocyte GFAP expression by TGF-beta1 and FGF-2. Glia 22, 202-210.

Robertson, E.J., 1987. Teratocarcinomas and Embryonic Stem Cells: A Practical Approach. IRL Press, Oxford.

Rodrigues Hell, R.C., Silva Costa, M.M., Goes, A.M. Oliveira, A.L, 2009. Local injection of BDNF producing mesenchymal stem cells increases neuronal survival and synaptic stability following ventral root avulsion. Neurobiol. Dis. 33, 290-300.

Romero, M.I., Rangappa, N., Garry, M.G., Smith, G.M., 2001. Functional regeneration of chronically injured sensory afferents into adult spinal cord after neurotrophin gene therapy. J. Neurosci. 21, 8408-8416.

Ruan, R.S., Leong, S.K., Yeoh, K.H., 1995. The role of nitric oxide in facial motoneurona death. Brain Res. 698, 163-168.

Sakamoto, T., Kawazoe, Y., Shen, J.S., Takeda, Y., Arakawa, Y., Ogawa, J., Oyanagi, K., Ohashi, T., Watanabe, K., Inoue, K., Eto, Y., Watabe, K., 2003. Adenoviral gene transfer of GDNF, BDNF and TGF beta 2, but not CNTF, cardiotrophin-1 or IGF1, protects injured adult motoneurons after facial nerve avulsion. J. Neurosci. Res. 72, 54-64.
Seabra Ferreira, R.J., 2014. Autologous or heterologous fibrin sealant scaffold: which is the better choice? J. Venomous Anim. Toxins Incl. Trop. Dis. 20, 31.

Shămardanova, G.F., Mukhamedshina, I.O., Rizvanov, A.A., Salafutdinov, I.I., Chelyshev, I.A., 2012. Effects of transplantation of human umbilical cord blood mononuclear cells, expressing VEGF and FGF2 genes, into the area of spinal cord traumatic lesion. Morfologiia 142, 31-36

Shihabuddin, L.S., Ray, J., Gage, F.H., 1997. FGF-2 is sufficient to isolate progenitors found in the adult mammalian spinal cord. Exp. Neurol. 148, 577-586.

Sinescu, C., Popa, F., Grigorean, V.T., Onose, G., Sandu, A.M., Popescu, M., Burnei, G., Strambu, V., Popa, C., 2010. Molecular basis of vascular events following spinal cord injury. J. Med. Life 3, 254-261.

Spejo, A.B., Carvalho, J.L., Goes, A.M., Oliveira, A.L., 2013. Neuroprotective effects of mesenchymal stem cells on spinal motoneurons following ventral root axotomy: synapse stability and axonal regeneration. Neuroscience 250, 715-732.

Takata, M., Nagahama, T., 1983. Synaptic efficacy of inhibitory synapses in hypoglossal motoneurons after transection of the hypoglossal nerves. Neuroscience 10, 23-29.

Teng, Y.D., Mocchetti, I., Wrathall, J.R., 1998. Basic and acidic fibroblast growth factors protect spinal motor neurones in vivo after experimental spinal cord injury. Eur. J. Neurosci. 10, 798-802.

Terlau, H., Seifert, W., 1990. Fibroblast growth factor enhances long-term potentiation in the hippocampal slice. Eur. J. Neurosci. 2, 973-977.

Thomson, J.A., Itskovitz-Eldor, J., Shapiro, S.S., Waknitz, M.A., Swiergiel, J.J., Marshall, V.S., Jones, J.M., 1998. Embryonic stem cell lines derived from human blastocysts. Science 282, 1145-1147.

Tsai, M.C., Shen, L.F., Kuo, H.S., Cheng, H., Chak, K.F., 2008. Involvement of acidic fibroblast growth factor in spinal cord injury repair processes revealed by a proteomics approach. Mol. Cell. Proteomics 7, 1668-1687.

Tzeng, S.F., Kahn, M., Liva, S., De Vellis, J., 1999. Tumor necrosis factor-alpha regulation of the Id gene family in astrocytes and microglia during CNS inflammatory injury. Glia $26,139-152$.

Walicke, P.A., 1988. Basic and acidic fibroblast growth factors have trophic effects on neurons from multiple CNS regions. J. Neurosci. 8, 2618-2627.

Watabe, K., Hayashi, Y., Kawazoe, Y., 2005. Peripheral nerve avulsion injuries as experimental models for adult motoneuron degeneration. Neuropathology 25, 371-380.

Weissman, I.L., 2000. Stem cells: units of development, units of regeneration, and units in evolution. Cell 100, 157-168.

Zai, L.J., Yoo, S., Wrathall, J.R., 2005. Increased growth factor expression and cell proliferation after contusive spinal cord injury. Brain Res. 1052, 147-155.

Zeng, X., Rao, M.S., 2007. Human embryonic stem cells: long term stability, absence of senescence and a potential cell source for neural replacement. Neuroscience 145, 1348-1358. 